\title{
HCN1 Channels Control Resting and Active Integrative Properties of Stellate Cells from Layer II of the Entorhinal Cortex
}

\author{
Matthew F. Nolan, ${ }^{1,2}$ Joshua T. Dudman, ${ }^{2}$ Paul D. Dodson, ${ }^{1}$ and Bina Santoro ${ }^{2}$ \\ ${ }^{1}$ Centre for Neuroscience Research, University of Edinburgh, Edinburgh EH8 9XD, United Kingdom, and ${ }^{2}$ Center for Neurobiology and Behavior, Columbia \\ University, New York, New York 10032
}

\begin{abstract}
Whereas recent studies have elucidated principles for representation of information within the entorhinal cortex, less is known about the molecular basis for information processing by entorhinal neurons. The HCN1 gene encodes ion channels that mediate hyperpolarizationactivated currents $\left(I_{\mathrm{h}}\right)$ that control synaptic integration and influence several forms of learning and memory. We asked whether hyperpolarization-activated, cation nonselective $1(\mathrm{HCN} 1)$ channels control processing of information by stellate cells found within layer II of the entorhinal cortex. Axonal projections from these neurons form a major component of the synaptic input to the dentate gyrus of the hippocampus. To determine whether HCN1 channels control either the resting or the active properties of stellate neurons, we performed whole-cell recordings in horizontal brain slices prepared from adult wild-type and HCN1 knock-out mice. We found that HCN1 channels are required for rapid and full activation of hyperpolarization-activated currents in stellate neurons. HCN1 channels dominate the membrane conductance at rest, are not required for theta frequency $(4-12 \mathrm{~Hz})$ membrane potential fluctuations, but suppress low-frequency $(<4 \mathrm{~Hz})$ components of spontaneous and evoked membrane potential activity. During sustained activation of stellate cells sufficient for firing of repeated action potentials, HCN1 channels control the pattern of spike output by promoting recovery of the spike afterhyperpolarization. These data suggest that HCN1 channels expressed by stellate neurons in layer II of the entorhinal cortex are key molecular components in the processing of inputs to the hippocampal dentate gyrus, with distinct integrative roles during resting and active states.
\end{abstract}

Key words: parahippocampal cortex; voltage-gated ion channels; neuronal excitability; spatial memory; $I_{\mathrm{h}}$; epilepsy

\section{Introduction}

To understand any neural circuit, one must understand not only the synaptic input and output arrangements but also the integrative properties of neurons at each point in the circuit. Neurons in the superficial layers of the entorhinal cortex occupy a pivotal position within the medial temporal lobe circuit used for encoding and retrieval of episodic memories. These neurons receive convergent inputs from associational areas of the neocortex (Amaral and Witter, 1989) and mediate the principal cortical input to the hippocampus (Dolorfo and Amaral, 1998; Witter et al., 2000). Neurons in layers II and III of the medial entorhinal cortex (MEC) provide the hippocampus with information about an animal's location, which they encode in a topographically or-

\footnotetext{
Received May 23, 2007; revised Sept. 25, 2007; accepted Sept. 25, 2007.

This work was supported by a Marie Curie Excellence grant (M.F.N.), The Italian Academy for Advanced Studies in America (B.S.), a Graduate Research Fellowship from the National Science Foundation (J.T.D.), a Human Frontie Science Program long-term fellowship (P.D.D.), funding from New York State Psychiatric Institute (Eric Kandel), and National Institutes of Health Grant NS36658 (Steven Siegelbaum). We thank Eric Kandel and Steve Siegelbaum for their generous support and advice, Mala Shah and Seb Thuault for comments on a previous version of this manuscript, and Alexei Morozov for $\mathrm{HCN1}^{-/-}$mice.

Correspondence should be addressed to Matthew F. Nolan, Centre for Neuroscience Research and Veterinary Biomedical Sciences, The Hugh Robson Building, University of Edinburgh, Edinburgh EH8 9XD, UK. E-mail: mattnolan@ed.ac.uk.

DOI:10.1523/JNEUROSCI.2358-07.2007

Copyright $\odot 2007$ Society for Neuroscience $\quad$ 0270-6474/07/2712440-12\$15.00/0
}

ganized grid-like representation (Leutgeb et al., 2005; Witter and Moser, 2006). Although knowledge of the functions of these neurons has evolved rapidly, the molecular underpinnings of the integrative processes through which they generate outputs useful to their downstream targets in the hippocampus remain unclear.

Layer II of the MEC contains two classes of neurons that project directly to the hippocampal dentate gyrus: stellate neurons and pyramidal neurons (Alonso and Klink, 1993; Klink and Alonso, 1997; Buckmaster et al., 2004). Stellate neurons have complex integrative properties that may enable these neurons to play unique roles in transformation of cortical representations (Alonso and Llinas, 1989; Alonso and Klink, 1993; Giocomo et al., 2007). Particular attention has focused on how persistent sodium currents $\left(I_{\mathrm{NaP}}\right)$ (White et al., 1998; Magistretti et al., 1999) and hyperpolarization-activated currents $\left(I_{\mathrm{h}}\right)$ influence the integrative properties of stellate neurons (Dickson et al., 2000). Yet, the molecular identities of the ion channels in stellate neurons that generate either $I_{\mathrm{h}}$ or $I_{\mathrm{NaP}}$ have not been established and the integrative functions of $I_{\mathrm{h}}$ in particular are not clear. For example, some computational models of stellate cells do not include any role at all for $I_{\mathrm{h}}$ (White et al., 1995, 1998), whereas others propose a central role for $I_{\mathrm{h}}$ (Dickson et al., 2000; Fransen et al., 2004). We were therefore interested to determine the molecular basis for the large $I_{\mathrm{h}}$ found in stellate neurons and to understand how ion 
channels mediating $I_{\mathrm{h}}$ influence the integrative properties of these neurons.

Channel subunits responsible for $I_{\mathrm{h}}$ are encoded by four genes, the hyperpolarization-activated, cation nonselective channel family (HCN1-4) (Robinson and Siegelbaum, 2003). HCN1 channels constrain memory processes that require the hippocampus or the prefrontal cortex (Nolan et al., 2004; Wang et al., 2007). In hippocampal pyramidal neurons, $I_{\mathrm{h}}$ is primarily mediated by HCN1 channels (Lorincz et al., 2002; Nolan et al., 2004) and is important for synaptic integration at resting membrane potentials (Magee, 2000). The functions of HCN1 channels at membrane potentials around the threshold for action potential firing are less clear. It is also unknown whether $\mathrm{HCN} 1$ channels in entorhinal stellate cells could influence behavior. Here, using immunohistochemical, electrophysiology, and genetic approaches, we demonstrate that $\mathrm{HCN} 1$ channels are expressed by stellate cells and may play distinct roles in information processing during resting and active states.

\section{Materials and Methods}

\section{Immunohistochemistry}

The use of mice in all experiments was in accordance with the institutional and national regulations. Brains were removed after perfusing mice, 7-18 weeks of age, with ice-cold artificial CSF (ACSF) or PBS, followed by $4 \%$ paraformaldehyde (PFA) in PBS. Vibratome-cut horizontal floating sections $(50 \mu \mathrm{m})$ were permeabilized by treating three times for 10 min with PBS plus $0.1 \%$ Triton X-100, followed by incubation in blocking solution (PBS plus 3\% normal goat serum) for $2 \mathrm{~h}$ at room temperature. Primary antibody incubation was performed in blocking solution overnight at $4^{\circ} \mathrm{C}$, using either of the following two anti-HCN1 antibodies: rabbit polyclonal anti-HCN1 (dilution 1:50; Alomone Labs, Jerusalem, Israel); rat monoclonal anti-HCN1 (dilution 1:25; clone IHR-7C3; generous gift from F. Müller and B. Kaupp, Institute for Neuroscience and Biophysics, Jülich, Germany). Slices were washed in PBS plus $0.1 \%$ Triton X-100 and incubated for $4 \mathrm{~h}$ at room temperature with the appropriate secondary antibody in blocking solution. Antibodies used were: rhodamine red-X-conjugated goat antirabbit IgG (dilution 1:200; Jackson ImmunoResearch, West Grove, PA), rhodamine red-X-conjugated goat anti-rat IgG (dilution 1:200; Jackson ImmunoResearch). After extensive washing, slices were mounted with Gel/Mount (Biomeda, Foster City, CA) and imaging performed using confocal microscopy. Both HCN1 antibodies yielded essentially identical staining patterns, and the pattern of HCN1 labeling was similar across the full age range examined. A subset of the immunohistochemical data, focusing only on expression of HCN1 in horizontal sections of the hippocampus, was described previously [Nolan et al. (2004), their supplemental Fig. 1f]. Anatomical identification of subdivisions of the hippocampal and parahippocampal regions is based on previous descriptions (van Groen et al., 2003).

\section{Electrophysiology}

Brain slices were prepared from 36- to 88-d-old mice. Electrophysiological recordings were obtained from slices prepared from mice with global deletion of the $\mathrm{HCN} 1$ channel $\left(\mathrm{HCN1}^{-/-}\right.$mice) or from their wild-type littermates $\left(\mathrm{HCN1}^{+/+}\right.$mice). Breeding strategies for generation of the mice have been described previously (Nolan et al., 2003). Experiments were interleaved so that recordings from different genotypes took place on alternate days. There was no significant difference between the ages of neurons from $\mathrm{HCN1}^{+/+}$and $\mathrm{HCN1}^{-/-}$mice used for either voltageclamp experiments $\left(\mathrm{HCN1}^{+/+}, 56.6 \pm 1.9 \mathrm{~d}, n=5 ; \mathrm{HCN1}^{-/-}, 54.6 \pm\right.$ $0.2 \mathrm{~d}, n=5 ; p=0.33)$ or current-clamp experiments $\left(\mathrm{HCN1}^{+/+}, 59.8 \pm\right.$ $\left.1.9 \mathrm{~d}, n=41 ; \mathrm{HCN1}^{-/-}, 57.8 \pm 1.9 \mathrm{~d}, n=43 ; p=0.46\right)$. Mice were decapitated, and their brains were removed rapidly and placed in cold $\left(4^{\circ} \mathrm{C}\right)$ modified ACSF composed of the following (in mM): $86 \mathrm{NaCl}, 1.2$ $\mathrm{NaH}_{2} \mathrm{PO}_{4}, 2.5 \mathrm{KCl}, 25 \mathrm{NaHCO}_{3}, 25$ glucose, $0.5 \mathrm{CaCl}_{2}, 7 \mathrm{MgCl}_{2}, 75$ sucrose. The hemisected brain was glued to an agar block and cut submerged under cold modified ACSF into $400 \mu \mathrm{m}$ sections with a Vibratome 3000 sectioning system. Slices were cut in a modified horizontal plane, with the rostral end of the brain tilted at an angle of $\sim 15-30^{\circ}$ in a dorsal direction and the dorsal surface of the brain tilted laterally by $\sim 10^{\circ}$. Slices were transferred to a storage container filled with standard ACSF at $33-35^{\circ} \mathrm{C}$ for $20-30 \mathrm{~min}$ and cooled to room temperature (20$22^{\circ} \mathrm{C}$ ). The standard ACSF had the following composition (in mM): 124 $\mathrm{NaCl}, 1.2 \mathrm{NaH}_{2} \mathrm{PO}_{4}, 2.5 \mathrm{KCl}, 25 \mathrm{NaHCO}_{3}, 20$ glucose, $2 \mathrm{CaCl}_{2}, 1 \mathrm{MgCl}_{2}$. For recording, slices were transferred to a submerged chamber, and stellate cells were visually identified under infrared illumination with DIC optics. Recordings of isolated $I_{\mathrm{h}}$ were made from stellate cells in ACSF of the following composition (in mM): $115 \mathrm{NaCl}, 1.2 \mathrm{NaH}_{2} \mathrm{PO}_{4}, 5 \mathrm{KCl}, 25$ $\mathrm{NaHCO}_{3}, 20$ glucose, $2 \mathrm{CaCl}_{2}, 1 \mathrm{MgCl}_{2}, 1 \mathrm{BaCl}_{2}, 0.1 \mathrm{CdCl}_{2}, 14-\mathrm{AP}, 5$ TEA, 0.005 NBQX, 0.02 bicuculline, and 0.0005 TTX. These recordings were performed at room temperature to facilitate comparison with data obtained from heterologously expressed channels. By comparison of currents recorded first at $24^{\circ} \mathrm{C}$ and subsequently at $35^{\circ} \mathrm{C}$, we estimated the Q10 value for the fast components of activation and deactivation of $I_{\mathrm{h}}$ in stellate cells to be $\sim 2.8$. All other electrophysiological experiments were performed at $33-35^{\circ} \mathrm{C}$ and were in the absence of pharmacological agents, unless stated otherwise.

Whole-cell recordings were obtained from the soma of stellate cells in MEC layer II using 2-5 $\mathrm{M} \Omega$ resistance electrodes filled with intracellular solution composed of the following (in $\mathrm{mM}$ ): $130 \mathrm{~K}$-methylsulfate, 10 $\mathrm{KCl}, 10$ HEPES, $2 \mathrm{MgCl}_{2}$, 0.1 EGTA, $4 \mathrm{Na}_{2} \mathrm{ATP}, 0.3 \mathrm{Na}_{2} \mathrm{GTP}, 10$ phosphocreatine. The electrophysiological and morphological properties of stellate cells recorded from mice were similar to previous descriptions made from stellate cells in slices obtained from rats and primates (Alonso and Klink, 1993; Klink and Alonso, 1997; Buckmaster et al., 2004) (supplemental Fig. 1, available at www.jneurosci.org as supplemental material). In most experiments, the intracellular solution also included biocytin (1\%). Stellate cells were identified before recording by a large soma located in the superficial part of layer II and by the presence of numerous primary dendrites with similar diameters. In contrast, pyramidal neurons in layer II were clearly identified by the presence of one primary dendrite with a relatively large diameter compared with the other dendrites (Klink and Alonso, 1997). As described in previous studies, stellate cell action potentials were followed by a characteristic large biphasic afterhyperpolarization (AHP) and showed little adaptation, whereas spikes fired by pyramidal neurons are followed by smaller afterhyperpolarizations and show strong adaptation (Alonso and Klink, 1993). After a subset of experiments, the identity of biocytin-filled neurons was confirmed by fixing the slice and staining the recorded neurons with either DAB (ABC kit; Vectastain) or with CY3-conjugated streptavidin (Jackson ImmunoResearch) (supplemental Fig. 1, available at www. jneurosci.org as supplemental material). Series resistances were $<15 \mathrm{M} \Omega$ for voltage-clamp experiments and $<40 \mathrm{M} \Omega$ for current-clamp experiments. There was no significant difference between the series resistance of recordings between experimental groups in either configuration. Series resistance in voltage-clamp recordings was compensated by $50-80 \%$. For current-clamp recordings, appropriate bridge and electrode capacitance compensation were applied. Membrane current and voltage were filtered at $1-2$ and $4-20 \mathrm{kHz}$ and sampled at 5-10 and $10-50$ $\mathrm{kHz}$ for voltage and current-clamp experiments, respectively. Experimentally measured liquid junction potentials of $+8.1 \mathrm{mV}$ (bath potential relative to the patch pipette) for the standard ACSF and $+7.5 \mathrm{mV}$ for the ACSF used to isolate $I_{\mathrm{h}}$ were not corrected for.

Data were analyzed in IGOR pro (WaveMetrics, Lake Oswego, OR) using Neuromatic (http://www.neuromatic.thinkrandom.com/) and custom written routines. Statistical analysis was performed using IGORpro or $\mathrm{R}$ (The $\mathrm{R}$ Foundation for Statistical Computing, www. $\mathrm{R}$-project.org). Unless indicated otherwise, mean values are $\pm \mathrm{SEM}$ (SEM). In figures in which error bars are absent, the SEM is smaller than the symbol size. Statistical significance was tested with Student's $t$ test, ANOVA, or an appropriate nonparametric test as indicated. In our analysis of the effects of 4-( $N$-ethyl- $N$-phenylamino)-1,2-dimethyl-6(methylamino) pyridinium chloride (ZD7288) on subthreshold membrane properties, we removed one $\mathrm{HCN1}^{+/+}$neuron that, in control conditions, had input resistance $>4$ SDs higher than the mean control value. This enabled us to more rigorously test the hypothesis that $\mathrm{HCN1}^{+/+}$and $\mathrm{HCN1}^{-/-}$neurons differ before, but not after, block of $I_{\mathrm{h}}$ 
(see Fig. 3E, F; see Table 2). When this neuron is also included in the analysis, we also find significant $(p<0.05)$ differences between $\mathrm{HCN1}^{+/+}$and $\mathrm{HCN1}^{-/-}$neurons in control conditions but not in the presence of ZD7288. To minimize possible slow-onset, nonspecific effects of ZD7288 (Chevaleyre and Castillo, 2002), all data during perfusion of ZD7288 were obtained within 5 min of the abolition of the membrane potential sag. For the experiments in Figures 6 and 7, this reduced the time available to sample firing patterns across a range of average frequencies, and so for these experiments, we focused only on obtaining data for average spike frequencies $<2 \mathrm{~Hz}$. For these experiments, only spikes occurring between 4 and $15 \mathrm{~s}$ after the onset of the $15 \mathrm{~s}$ duration current step were analyzed.

Analysis of hyperpolarization-activated currents. To estimate the steady-state activation of $I_{\mathrm{h}}$, the amplitude of tail currents after voltage steps to a series of test potentials were fit with the following modified form of the Boltzmann equation: $I_{\text {tail }}=A /\left(1+\exp \left[\left(V-V_{1 / 2}\right) / \mathrm{s}\right]\right)$, where $A$ is the maximal tail current amplitude (in $\mathrm{pA}$ ), $V$ is the membrane voltage during the test pulse (in $\mathrm{mV}$ ), $V_{1 / 2}$ is the midpoint activation voltage (in $\mathrm{mV}$ ), and $\mathrm{s}$ is the slope (in $\mathrm{mV}$ ). Activation curves were fit with a single exponential of the form $I=I_{\text {offset }}+A \exp (-t / \tau)$, or a double exponential of the form $I=I_{\text {offset }}+A_{\text {fast }} \exp \left(-t / \tau_{\text {fast }}\right)+$ $A_{\text {slow }} \exp \left(-t / \tau_{\text {slow }}\right)$. Residual currents were obtained by subtraction of the fit from the data. Because of the smaller amplitude of $I_{\mathrm{h}}$ in cells from $\mathrm{HCN1}^{-/-}$mice, we were only able to accurately fit exponential functions to the activation phase of $I_{\mathrm{h}}$ at test potentials negative to $-85 \mathrm{mV}$.

Analysis of subthreshold membrane potential activity. Input resistance, membrane time constant, and sag were estimated from membrane potential responses to small ( $<40 \mathrm{pA}$ ) current steps (Nolan et al., 2004). Power spectra were calculated using routines included with IGORpro. Spectrograms were calculated, using custom written routines, from individual power spectra obtained from overlapping segments of each membrane potential recording. Each segment had a duration of $4 \mathrm{~s}$ and began $0.5 \mathrm{~s}$ after the start of the previous segment. To investigate how neurons respond to different frequencies of input, we examined membrane potential responses to oscillating current inputs with frequency increasing to a maximum of $25 \mathrm{~Hz}$ over a total duration of $20 \mathrm{~s}$ (ZAP currents) (Puil et al., 1986). To calculate the membrane impedance, the Fourier transform of the membrane voltage response was divided by the Fourier transform of the input current. The complex valued result was converted into magnitude and phase components. For a typical stellate cell, the relationship between impedance magnitude and input frequency typically contains a "resonant" peak (Erchova et al., 2004). We quantified the degree of resonance using a ratio, $q$, defined as the peak impedance amplitude divided by the impedance amplitude for an input frequency of $0.5 \mathrm{~Hz}$. The resonant frequency was defined as the input frequency corresponding to the peak impedance magnitude. In the description of our data, we refer to the impedance magnitude simply as the impedance $(Z)$. We confirmed the accuracy of the impedance values estimated from responses to ZAP current inputs by comparison with estimates obtained from responses to inputs oscillating at frequencies of $1,5,10$, and $20 \mathrm{~Hz}$ ( $n=5$ stellate cells).

Analysis of spike patterns. Because in each neuron the pattern of spikes fired was strongly dependent on the overall firing rate, we evaluated firing patterns across a range of mean firing rates up to $5 \mathrm{~Hz}$ (see Figs. 6, 7). During positive currents steps, of duration $20 \mathrm{~s}$, both the pattern and frequency of spikes fired depended on the amplitude of the current step. We analyzed in detail the pattern of spikes fired from 4 to $20 \mathrm{~s}$ after the onset of suprathreshold current steps, as the mean spike frequency is approximately stationary during this period and does not differ between
B

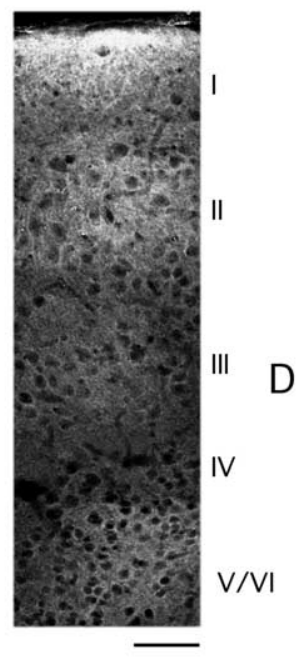

C

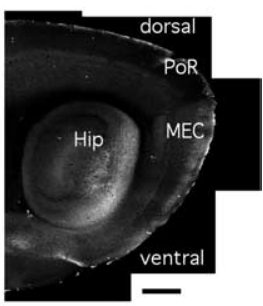

D

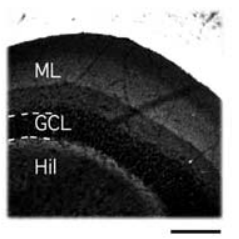

Figure 1. Distribution of $\mathrm{HCN} 1$ channels in the medial temporal lobe. $\boldsymbol{A}$, Montage of low-magnification images demonstrating the distribution of HCN1 labeling in the hippocampus, parahippocampal regions, and adjacent neocortex in horizontal sections granule cell layer; Hil, hilus; Hip, hippocampus; LEC, lateral entorhinal cortex; ML, molecular layer; Para, parasubiculum; PoR, postrhinal cortex; PR, perirhinal cortex; Pre, presubiculum; Sub, subiculum. Scale bars: $\boldsymbol{A}, \boldsymbol{C}, 500 \mu \mathrm{m} ; \boldsymbol{B}, 50 \mu \mathrm{m} ; \boldsymbol{D}, 100 \mu \mathrm{m}$.

$\mathrm{HCN1}^{+/+}$and $\mathrm{HCN1}^{-/-}$mice (supplemental Fig. 3, available at www. jneurosci.org as supplemental material). Data summarizing the properties of spike trains were sorted into bins of width $1 \mathrm{~Hz}$ according to the mean spike frequency during the analysis period. To quantify the tendency for neurons to generate clustered patterns of spikes, we used two definitions for a cluster of spikes: a "relaxed" definition favored detection of clustered patterns at higher mean firing rates, whereas a "stringent" definition favored detection of clusters that were well isolated from surrounding spikes. Thus, in the relaxed condition, a cluster of spikes was defined as two or more consecutive spikes with interspike interval $<250$ $\mathrm{ms}$, preceded and followed by silent periods of duration $>300 \mathrm{~ms}$, whereas in the stringent condition, a cluster was defined as two or more consecutive spikes with interspike interval $<250 \mathrm{~ms}$, preceded and followed by silent periods of duration $>500 \mathrm{~ms}$. We estimated the probability that a spike occurs as part of a cluster $\left(P_{C}\right)$ from the ratio of the number of spikes that occur within clusters to the total number of spikes. Throughout this study, the term "average spike frequency" refers to the overall frequency of spikes during an analysis period, whereas average intracluster spike frequency refers only to the frequency of spikes within clusters.

\section{Results}

\section{Localization of HCN1 channels in the medial temporal lobe circuit}

We first examined the distribution of $\mathrm{HCN} 1$ channel protein in the hippocampal-entorhinal circuit. We found consistent patterns of HCN1 labeling in horizontal and parasagittal brain sections from wild-type $\left(\mathrm{HCN1}^{+/+}\right)$mice (horizontal, $n=4$; parasagittal, $n=2$ ), whereas HCN1 labeling was completely absent from global HCN1 knock-out $\left(\mathrm{HCN1}^{-1-}\right)$ mice $(n=4 ; n=1)$ (Fig. $1 A$ ). In both horizontal and parasagittal planes, the medial entorhinal cortex contains a distinct laminar distribution of HCN1 channels (Fig. 1A-C). As in the neocortex, strong HCN1 labeling is present in the superficial part of layer I of the MEC. This is consistent with the preferential subcellular localization of HCN1 channels to the distal apical dendrites of cortical pyramidal neurons (Lorincz et al., 2002). However, in contrast to the neocortex, significant HCN1 labeling is also present within layer 

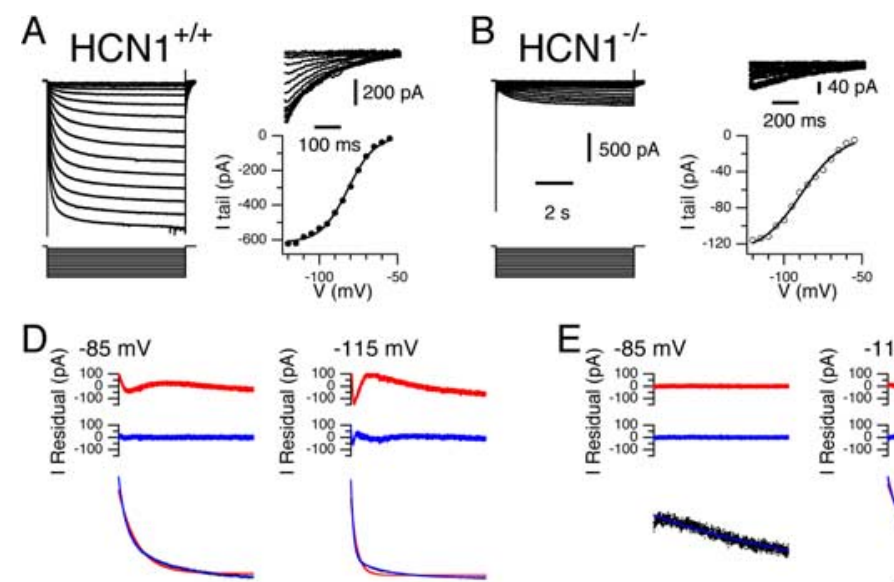

$\mathrm{F}$

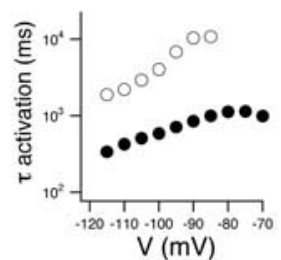

G
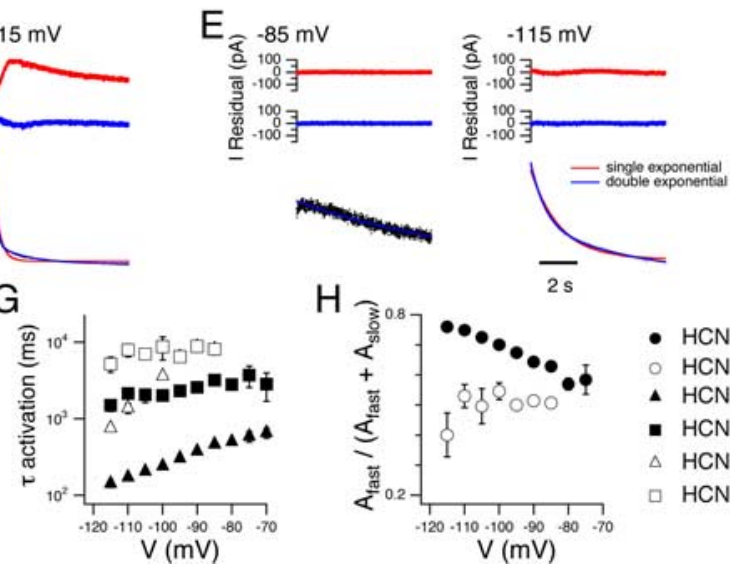
$\mathrm{V}(\mathrm{mV})$

Figure 2. Full and rapid activation of $I_{\mathrm{h}}$ requires $\mathrm{HCN} 1$ channels. $\boldsymbol{A}, \boldsymbol{B}$, Examples of $I_{\mathrm{h}}$ recorded from MEC layer II stellate cells from $H C N 1^{+/+}(\boldsymbol{A})$ and $H C N 1^{-/-}(\boldsymbol{B})$ mice. Each set of traces shows current responses (top) to hyperpolarizing voltage steps (bottom) from a holding potential of $-50 \mathrm{mV}$. The amplitudes of the tail currents (right top) after each voltage step are plotted as a function of the test potential (right bottom) and fit with a two-state Boltzmann function. The scale for the current traces in $\boldsymbol{A}$ (left) is the same as for $\boldsymbol{B}$ (left). $\boldsymbol{C}$, The mean tail current amplitude, shown plotted as a function of test potential, is significantly larger in neurons from $H C N 1^{+/+}$compared with $H C N 1^{-/-}$mice $(p<0.05 ; n=5) . \boldsymbol{D}, \boldsymbol{E}$, Examples, from $H C N 1^{+/+}$mice $(\boldsymbol{D})$ and $H C N 1^{-1-}$ mice $(\boldsymbol{E})$, of $I_{\mathrm{h}}$ activation fit with either a single exponential or the sum of two exponentials for steps to -85 or -115 $\mathrm{mV}$ (bottom). Also shown are the residual currents obtained after fitting $I_{\mathrm{h}}$ activation with a single exponential (top) or the sum of two exponentials (middle). Whereas activation of $/ \mathrm{h}$ from $\mathrm{HCN} 1^{+/+}$mice is better fit with a sum of two exponentials, rather than with a single exponential, activation of $I_{\mathrm{h}}$ in cells from $\mathrm{HCN}^{-/-}$mice can be adequately fit with a single exponential function, except at potentials negative to $-100 \mathrm{mV}$. $\boldsymbol{F}$, Plot of mean time constants obtained by fitting $I_{\mathrm{h}}$ activation with a single exponential as a function of test potential. Activation of $I_{\mathrm{h}}$ from $\mathrm{HCN}^{+/+}(n=5)$ mice is significantly $(p<0.001)$ faster than for $H C N 1^{-1-}$ mice $(n=4)$. After return to the holding potential of $-50 \mathrm{mV}$ after steps to $-115 \mathrm{mV}$, deactivation of $/ \mathrm{h}$ is fit well with a single exponential function with a time constant of $182.4 \pm 40.1$ and $612.4 \pm 40.9$ ms in stellate cells from $H C N 1^{+/+}$and $H C N 1^{-1-}$ mice, respectively (data not shown) $(p<0.01)$. G. The mean fast and slow time constants obtained by fitting $I_{\mathrm{h}}$ activation with a sum of two exponentials are plotted as a function of test potential. Slow $(p<0.05)$ and fast $(p<0.0001)$ time constants were shorter for stellate cells from $\mathrm{HCN1}^{+/+}$compared with $\mathrm{HCN1}^{-/-}$mice. $\boldsymbol{H}$, Plot of the ratio of the amplitudes of the fast and slow time constants obtained from a double exponential fit as a function of test potential. The ratio was higher for $H C N 1^{+/+}$versus $H C N 1^{-/-}$mice $(p<0.01)$.

II of the MEC. Layer II contains the cell bodies of stellate and pyramidal neurons that project to the dentate gyrus as well as the apical dendrites of pyramidal cells from deeper layers of the entorhinal cortex. HCN1 labeling was also present at the site of termination of axons from neurons in layer II of the MEC in the middle third of the molecular layer of the dentate gyrus (Fig. 1D). Because dentate granule cells do not express HCN1 mRNA (Santoro et al., 2000), the HCN1 signal in this region may originate from the axons of layer II MEC neurons (Bender et al., 2007). Together, these histological data suggest that HCN1 channels influence computations in several parts of the parahippocampal circuit and point to a unique function for HCN1 channels in layer II of the medial entorhinal cortex compared with other cortical areas.

Rapid and full activation of $I_{\mathrm{h}}$ in layer II stellate cells requires HCN1 channels

The prominent $\mathrm{HCN} 1$ labeling in layer II of the MEC led us to ask whether HCN1 channels contribute to $I_{\mathrm{h}}$ in MEC layer II stellate cells. We recorded $I_{\mathrm{h}}$ using conditions designed to reduce contamination by other membrane currents (see Materials and
C

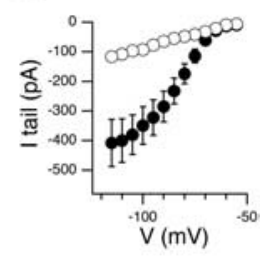

- $\mathrm{HCN}^{+/+}$

- $\mathrm{HCN}^{\%}$

- $\mathrm{HCN1}^{+/+} \tau_{\text {fast }}$

- $\mathrm{HCN1}^{+/+} \tau_{\text {slow }}$

$\triangle \mathrm{HCN}^{-\%} \tau_{\text {fast }}$

․ $\mathrm{HCN}{ }^{\%} \tau_{\text {slow }}$

Methods). As in previous studies of MEC layer II cells from rats (Dickson et al., 2000; Richter et al., 2000), hyperpolarizing voltage steps activate a large $I_{\mathrm{h}}$ in stellate cells from $\mathrm{HCN1}^{+/+}$mice (Fig. 2A). Data obtained from $\mathrm{HCN1}^{+/+}$stellate cells by fitting a Boltzmann function to $I_{\mathrm{h}}$ tail currents reveal a maximum amplitude of $410 \pm 77 \mathrm{pA}$, a half-maximum activation potential of $-83.1 \pm 0.9 \mathrm{mV}$, and a slope of $8.1 \pm 0.1 \mathrm{mV}$, whereas a similar fit for data from $\mathrm{HCN1}^{-1-}$ mice yields a maximum amplitude that is greatly reduced to $138 \pm 10 \mathrm{pA}(p<0.01)$, a half-maximum activation potential that is shifted in a negative direction to $-90.1 \pm 0.9 \mathrm{mV}(p<$ $0.001)$ and a more shallow slope of $15.1 \pm$ $0.9 \mathrm{mV}(p<0.0001)$ (Fig. $2 A-C)$. Thus, in MEC layer II stellate cells, $\mathrm{HCN} 1$ channels determine the voltage dependence of activation of $I_{\mathrm{h}}$ and are required for maximal activation of the current.

We next asked whether deletion of HCN1 modifies the kinetics of $I_{\mathrm{h}}$ in MEC layer II stellate cells. We found that the gating properties of $I_{\mathrm{h}}$ in neurons from $\mathrm{HCN1}^{+/+}$mice are intermediate between those of homomeric HCN1 and HCN2 channels but more closely resemble the kinetics of channels formed by heteromeric assembly of $\mathrm{HCN} 1$ and $\mathrm{HCN} 2$ subunits (Santoro et al., 2000; Chen et al., 2001; Ulens and Tytgat, 2001) (Fig. 2D, F-H). In contrast to $\mathrm{HCN1}^{+/+}$mice, the kinetics of activation and deactivation of $I_{\mathrm{h}}$ in cells from $\mathrm{HCN1}^{-1-}$ mice are much slower $(p<0.05)$ (Fig. $2 F-H)$. Thus, HCN1 channels in layer II stellate neurons are required for the relatively rapid activation and deactivation of the wild-type current, in addition to determining the steady-state activation properties of $I_{\mathrm{h}}$. The presence of a residual current in stellate cells from $\mathrm{HCN1}^{-/-}$mice indicates that, in addition to HCN1 channels, other HCN subunits contribute to the native current. This is consistent with low levels of HCN2 and HCN3 protein in the MEC (Notomi and Shigemoto, 2004).

\section{HCN1 channels shape the resting membrane properties of entorhinal layer II stellate cells}

Because we found that HCN1 channels are responsible for a major component of $I_{\mathrm{h}}$ in MEC layer II stellate cells, we asked whether deletion of HCN1 channels influences the resting membrane properties of these neurons (Fig. 3). These and all additional experiments were performed in standard ACSF at $33-36^{\circ} \mathrm{C}$.

Deletion of HCN1 channels from MEC layer II stellate cells has several profound effects on their resting membrane properties (Fig. 3, Table 1). Stellate cells from both groups of mice do not fire spontaneous action potentials. However, in contrast to stellate cells from $\mathrm{HCN1}^{+/+}$mice, those from $\mathrm{HCN1}^{-/-}$mice have significantly more negative resting membrane potentials $(p \ll$ 0.0001 ), a significantly higher input resistance measured from 
responses to either negative ( $p \ll 0.0001$ ) or positive $(p<0.0001)$ current steps and a longer membrane time constant $(p \ll$ 0.0001 ). The sag and rebound responses of stellate cells from $\mathrm{HCN1}^{-/-}$mice have significantly reduced amplitude and slower kinetics (Fig. 3C,D; Table 1). These effects of deletion of HCN1 suggest a large contribution of channels containing HCN1 subunits to the resting membrane conductance of stellate cells.

If $\mathrm{HCN}$ channels in MEC stellate cells are indeed open at resting potentials, then acute pharmacological block of $I_{h}$ should modify their resting membrane properties. In addition, if deletion of HCN1 channels does not have secondary effects on the resting membrane properties of MEC stellate cells, for example resulting from upregulation or downregulation of other membrane ion channels, then the properties of neurons from $\mathrm{HCN1}^{+/+}$and $H C N 1^{-/-}$mice should not differ when $I_{\mathrm{h}}$ is blocked pharmacologically. We therefore evaluated the effects of blocking $I_{\mathrm{h}}$ with ZD7288 (BoSmith et al., 1993; Maccaferri and McBain, 1996). Consistent with previous studies of stellate cells from rats (Klink and Alonso, 1993; Jones, 1994; van Der Linden et al., 1999; Dickson et al., 2000), perfusion of ZD7288 quickly reduced the sag, increased the input resistance, and caused a profound hyperpolarization of the membrane potential of stellate cells from both groups of mice (Fig. $3 E, F$; Table 2). From the differences in input resistance measured at the control resting membrane potential in the presence and absence of ZD7288, we estimate that $I_{\mathrm{h}}$ contributes to $\sim 55$ and $20 \%$ of the resting membrane conductance in stellate cells from $\mathrm{HCN1}^{+/+}$and $\mathrm{HCN1}^{-/-}$mice, respectively. Importantly, in the presence of ZD7288, the membrane properties of stellate cells from $\mathrm{HCN1}^{+/+}$and $\mathrm{HCN1}^{-/-}$mice were indistinguishable (Table 2), providing strong evidence that deletion of HCN1 channels does not cause secondary changes to the membrane properties of these neurons.

\section{HCN1 channels suppress resting membrane potential fluctuations but are not required for theta frequency perithreshold activity}

Because recordings made in vivo from cortical neurons indicate that integration of synaptic responses may occur both at resting membrane potentials and at depolarized membrane potentials close to spike threshold (Steriade et al., 1993; Cossart et al., 2003; Waters and Helmchen, 2006), sometimes referred to as "upstates," we were interested to determine whether HCN1 channels could also influence the integrative properties of stellate cells at membrane potentials around spike threshold. Previous experimental and computational studies have concluded that interactions between $\mathrm{HCN}$ currents and $I_{\mathrm{NaP}}$ drive theta frequency perithreshold membrane potential oscillations (Alonso and Llinas, 1989; Dickson et al., 2000; Fransen et al., 2004). However, we found that the amplitude of theta frequency fluctuations was similar for stellate cells from $\mathrm{HCN1}^{+/+}$and $\mathrm{HCN1}^{-/-}$mice, whereas the amplitude of low frequency $(<4 \mathrm{~Hz})$ fluctuations at

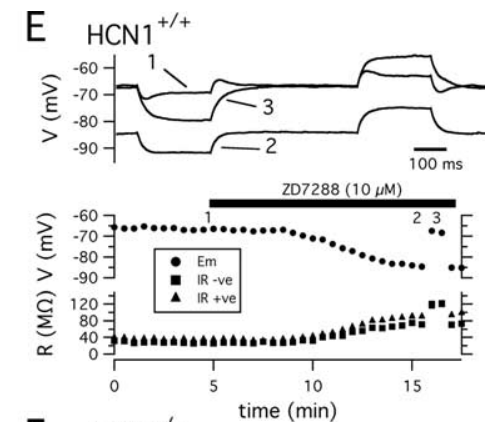

F $\mathrm{HCN} 1^{-1-}$
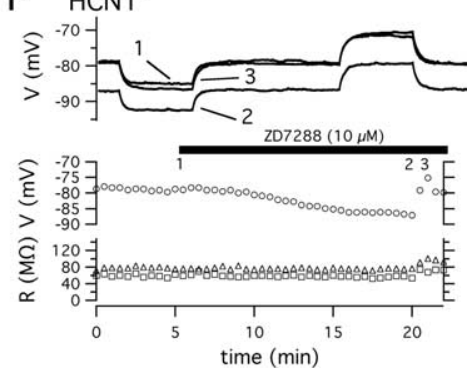
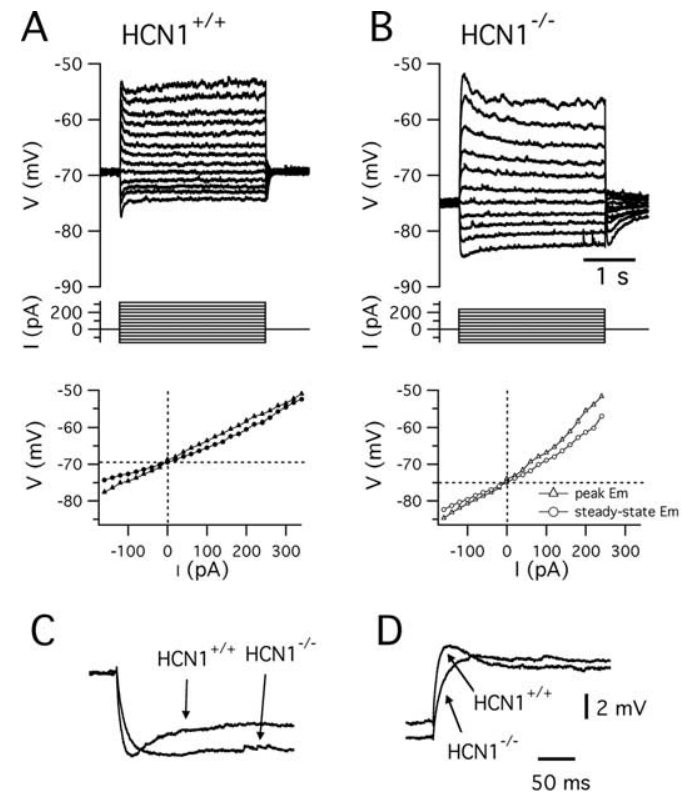

Figure 3. $\mathrm{HCN} 1$ channels dominate the resting integrative properties of layer Il stellate cells. $A, B$, Examples from $\mathrm{HCN1}^{+/+}(\boldsymbol{A})$ ( bottom graphs. The depolarization of the membrane potential to control values at the end of each experiment was achieved by introducing a constant amplitude offset current.

Table 1. Membrane properties of MEC stellate cells from $\mathrm{HCN1}^{+/+}$and $\mathrm{HCN1}^{-/-}$ mice

\begin{tabular}{lccl}
\hline & \multicolumn{1}{c}{$H C N 1^{+/+}$} & \multicolumn{1}{c}{$H C N 1^{-/-}$} & $p$ \\
\hline Resting membrane potential $(\mathrm{mV})$ & $-68.5 \pm 0.6$ & $-75.0 \pm 0.5$ & $5.2 \mathrm{e}-13$ \\
Input resistance $(-\mathrm{ve})(\mathrm{M} \Omega)$ & $43.9 \pm 3.2$ & $73.2 \pm 4.7$ & $2.8 \mathrm{e}-6$ \\
Input resistance $(+\mathrm{ve})(\mathrm{M} \Omega)$ & $55.2 \pm 3.9$ & $87.3 \pm 7.1$ & $1.8 \mathrm{e}-4$ \\
Time constant $(-\mathrm{ve})(\mathrm{ms})$ & $9.3 \pm 0.9$ & $20.4 \pm 1.3$ & $6.1 \mathrm{e}-10$ \\
Time constant (+ve) (ms) & $10.3 \pm 0.8$ & $19.8 \pm 1.6$ & $1.1 \mathrm{e}-6$ \\
Sag & $0.62 \pm 0.01$ & $0.80 \pm 0.01$ & $1.2 \mathrm{e}-17$ \\
\hline
\end{tabular}

Input resistance and membrane time constant were calculated from membrane potential responses to negative current steps ( - ve) and positive current steps ( + ve). The membrane potential sag ratio (Sag) was calculated from responses to negative current steps. For $\mathrm{HCN}^{+/+}$mice, $n=45$ for resting potential and input resistance and $n=$ 41 otherwise. For $\mathrm{HCN}^{-1-}$ mice, $n=53$ for resting potential and input resistance and $n=43$ for other properties.

membrane potentials negative to $-60 \mathrm{mV}$ is larger for neurons from $\mathrm{HCN1}^{-/-}$compared with $\mathrm{HCN1} 1^{+/+}$mice (Fig. 4).

To determine whether the larger low frequency membrane potential fluctuations observed in the absence of HCN1 channels can be accounted for by altered responsiveness of neurons from $\mathrm{HCN1}^{-1-}$ mice to inputs that fluctuate at low frequencies, we examined membrane potential responses to injection of oscillating inputs with continuously increasing frequency (ZAP functions) (Fig. 5). In agreement with observations from rats (Erchova et al., 2004), membrane potential responses of stellate cells from $\mathrm{HCN1}^{+/+}$mice demonstrate clear resonant peaks at frequencies in the range of $4-8 \mathrm{~Hz}$. In contrast, clear resonant peaks were not observed from stellate cells from $\mathrm{HCN1}^{-1-}$ mice, but rather the magnitude of the membrane impedance for inputs with frequencies $<4 \mathrm{~Hz}$ was substantially increased compared with $\mathrm{HCN} 1^{+/+}$mice (Fig. $5 G-J$ ). Therefore, expression of HCN1 channels suppresses responses of stellate cells to inputs that fluctuate at frequencies $<4 \mathrm{~Hz}$ by reducing the membrane imped- 
Table 2. Summary of the effects of ZD7288 on the resting membrane properties of stellate neurons from $\mathrm{HCN1}^{+/+}(n=7)$ and $\mathrm{HCN1}^{-/-}$mice $(n=6)$

\begin{tabular}{|c|c|c|c|}
\hline & Control & ZD7288 & ZD7288 offset \\
\hline \multicolumn{4}{|l|}{$\mathrm{HCN1}^{+/+}$} \\
\hline$V_{\mathrm{m}}(\mathrm{mV})$ & $-70.1 \pm 1.3$ & $-81.9 \pm 1.5$ & $-70.0 \pm 1.3$ \\
\hline $\mathbb{I R}$-ve $(M \Omega)$ & $39.9 \pm 3.5$ & $72.9 \pm 5.3$ & $106.2 \pm 11.9$ \\
\hline $\mathrm{IR}+$ ve $(\mathrm{M} \Omega)$ & $53.3 \pm 6.2$ & $100.9 \pm 11.4$ & $137.9 \pm 15.2$ \\
\hline \multicolumn{4}{|l|}{$\mathrm{HCN1}^{-1-}$} \\
\hline$V_{\mathrm{m}}(\mathrm{mV})$ & $-75.8 \pm 0.8$ & $-83.3 \pm 1.5$ & $-76.1 \pm 1.0$ \\
\hline $\mathbb{I R}-$ ve $(M \Omega)$ & $78.7 \pm 9.2$ & $79.6 \pm 10.2$ & $98.9 \pm 12.8$ \\
\hline $\mathrm{IR}+\mathrm{ve}(\mathrm{M} \Omega)$ & $107.5 \pm 15.9$ & $115.6 \pm 18.6$ & $145.0 \pm 22.9$ \\
\hline
\end{tabular}

The membrane potential $\left(V_{\mathrm{m}}\right)$ along with input resistance determined from positive ( $\left.\mathrm{R}+\mathrm{ve}\right)$ and negative (IR-ve) current steps were first estimated in control conditions and then in the presence of $10 \mu \mathrm{m} \mathrm{ZD7288}$ without any offset current (ZD7288) and also with the membrane potential returned to its control value by injection of a constant offset current (ZD7288 offset). ANOVA demonstrated significant effects of both genotype and ZD7288 on $V_{\mathrm{m}}(p=0.013$ and $p=1 \mathrm{e}-7), \mathrm{IR}-\mathrm{ve}(p=0.004$ and $p=0.018), \mathrm{IR}+\mathrm{ve}(p=0.016$ and $p=0.037)$, and sag $(p=$ $1 \mathrm{e}-6$ and $p=1 \mathrm{e}-7)$. Post hoc analysis ( $t$ test) indicates that, in control conditions, there are significant differences between stellate cells from $\mathrm{HCN1}^{+/+}$and $\mathrm{HCN1}^{-/-}$mice in their $V_{\mathrm{m}}(p=0.0038)$, IR-ve $(p=0.0066)$ $\mathbb{I R}+\mathrm{ve}(p=0.017)$, and sag $(p=0.0005)$. In contrast, in the presence of ZD7288, there are no longer any significant differences between $\mathrm{HCN1}^{+/+}$and $\mathrm{HCN1} 1^{-/-}$mice in $V_{\mathrm{m}}(p=0.51), \mathrm{IR}-$ ve $(p=0.58)$, or $\mathrm{IR}+$ ve $(p=0.52)$.

ance in this frequency range. This is consistent with previous demonstrations of the contribution of HCN currents to resonant properties of cortical pyramidal neurons (Hutcheon et al., 1996; Ulrich, 2002).

Deletion of HCN1 channels did not lead to changes in the persistent $\mathrm{Na}^{+}$current (supplemental Fig. 2, available at www. jneurosci.org as supplemental material) or the membrane potential threshold or waveform of the action potential (supplemental Fig. 3, available at www.jneurosci.org as supplemental material), indicating that the failure of deletion of HCN1 to abolish membrane potential fluctuations is not a result of adaptation by other membrane conductances active at potentials around spike threshold. The kinetics of the residual HCN current in stellate cells from $\mathrm{HCN1}^{-/-}$mice are not fast enough to generate theta frequency membrane potential fluctuations according to previously proposed models (Alonso and Llinas, 1989; Dickson et al., 2000; Fransen et al., 2004). Rather, the previous experimental observation that $I_{\mathrm{h}}$ blockers abolish oscillations may be explained by a failure to evaluate oscillatory activity at comparable membrane potentials (supplemental Fig. 4, available at www. jneurosci.org as supplemental material) or to effects of pharmacological blockers of $I_{\mathrm{h}}$ on other ion channels (Chevaleyre and Castillo, 2002; Do and Bean, 2003; Felix et al., 2003; Chen, 2004).

Thus, together, our data indicate that the fast component of $I_{\mathrm{h}}$ is not required for theta frequency perithreshold membrane potential fluctuations but instead suppresses low frequency $(<4$ $\mathrm{Hz}$ ) activity at membrane potentials close to rest (Figs. 4, 5). These data are consistent with models of entorhinal stellate cells that generate theta frequency perithreshold membrane potential fluctuations, without requiring the presence of $I_{\mathrm{h}}$ but through stochastic gating of ion channels that mediate a persistent sodium conductance (White et al., 1998; Dorval and White, 2005).

\section{The pattern of action potentials fired by stellate cells is modified by deletion of HCN1 channels}

Although HCN1 channels do not appear to be required for perithreshold theta frequency fluctuations in the membrane potential of stellate cells in the entorhinal cortex, could they nevertheless influence active states of these neurons through some other mechanism? Stellate cells often fire clusters of two or more spikes at a relatively high frequency surrounded by periods of inactivity (Alonso and Klink, 1993; White et al., 1998) (Fig. 6A), suggesting that as well as encoding information in the frequency of their output, stellate cells may also take advantage of intrinsically generated patterns of activity to communicate with downstream neurons. Because the mechanisms that control the patterns of spike output or the influence of $I_{\mathrm{h}}$ are not clear, we asked whether deletion of $\mathrm{HCN} 1$ channels modifies patterns of spikes fired by entorhinal stellate cells (Fig. 6).

To quantify patterns of spikes, we calculated the probability that a spike occurs as part of a cluster $\left(P_{C}\right)$, the number of spikes per cluster, and the intracluster spike frequency (see Materials and Methods). At spike firing frequencies that correspond to those recorded from superficial entorhinal cells in behaving animals (Fyhn et al., 2004; Hafting et al., 2005), using either relaxed or stringent definitions of a spike cluster (see Materials and Methods), we found that $P_{C}$, the number of spikes per cluster, and the intracluster spike frequency all vary as a function of the average spike frequency (Fig. 6C-E). After accounting for the average spike frequency, we found significant differences between $\mathrm{HCN1}^{-/-}$compared with $\mathrm{HCN1}{ }^{+/+}$mice in $P_{C}$ (Fig. $6 \mathrm{C}$ ) and the intracluster spike frequency (Fig. $6 \mathrm{D}$ ). Analysis using the relaxed cluster definition also suggested that deletion of HCN1 channels modifies the number of spikes per cluster, but this difference was not significant using the stringent cluster definition (Fig. 6E). The effect of HCN1 deletion on $P_{C}$ reflects reduced occurrence of clustered patterns of activity at average spike frequencies between 1 and $3 \mathrm{~Hz}$, where clustered patterns are usually most prominent (Fig. 6C). The difference between genotypes in the mean frequency of spikes within a cluster is caused by significantly lower intracluster spike frequencies in neurons from $\mathrm{HCN1}^{-/-}$compared with $\mathrm{HCN}^{+/+}$mice (Fig. $6 \mathrm{D}$ ). Consistent with the modified firing properties of stellate cells from HCN1 knock-out animals being directly attributable to the absence of HCN1 channels, rather than to secondary adaptive changes, perfusion of the $I_{\mathrm{h}}$ blocker ZD7288 also reduced $P_{C}$ (Fig. $6 F, G$ ). Thus, HCN1 channels appear to modify the pattern of spike output from stellate cells by promoting the emergence of clustered spike patterns and by increasing the spike frequency within a cluster.

\section{HCN1 channels accelerate recovery from the action potential afterhyperpolarization}

How are HCN1 channels able to control patterns of spike output from stellate neurons? In all stellate neurons, single action potentials are followed by a fast AHP and a slower medium AHP (Alonso and Klink, 1993) (Fig. 7). We find that rapid recovery from the medium AHP appears to be important for generation of clustered patterns of activity, because clustered patterns of spikes involve initiation of a second action potential shortly after recovery from the preceding AHP (Fig. $6 A, B$ ), and the half-width of the AHP correlates strongly with $P_{C}$ (Fig. $\left.7 F\right)$.

Because the AHP reaches potentials at which $I_{\mathrm{h}}$ is activated, we wondered whether $\mathrm{HCN} 1$ channels may influence firing patterns by controlling the waveform of the AHP. In contrast to $\mathrm{HCN1}^{+/+}$ mice (Fig. $7 \mathrm{~A}, \mathrm{~B}$ ), the AHP half-width of neurons from $\mathrm{HCN1}^{-/-}$ mice (Fig. 7C,D) is significantly longer at average firing frequencies below $3 \mathrm{~Hz}$ (Fig. 7E), suggesting that HCN1 channels influence spike output by accelerating recovery from the AHP. In support of this conclusion, acute block of HCN channels by perfusion of $10 \mu \mathrm{M} Z \mathrm{ZD} 7288$ also increased the duration of the action potential AHP (Fig. 7G,H). Because deletion of HCN1 channels did not alter the current threshold required to evoke action potentials, the voltage threshold, amplitude, or half-width of the action potential, the amplitude of fast or medium components of the AHP or the relationship between injected current and the number or frequency of spikes fired (supplementary Fig. 3, available at www.jneurosci.org as supplemental material), differences in the AHP duration are not secondary to a change in a preceding 

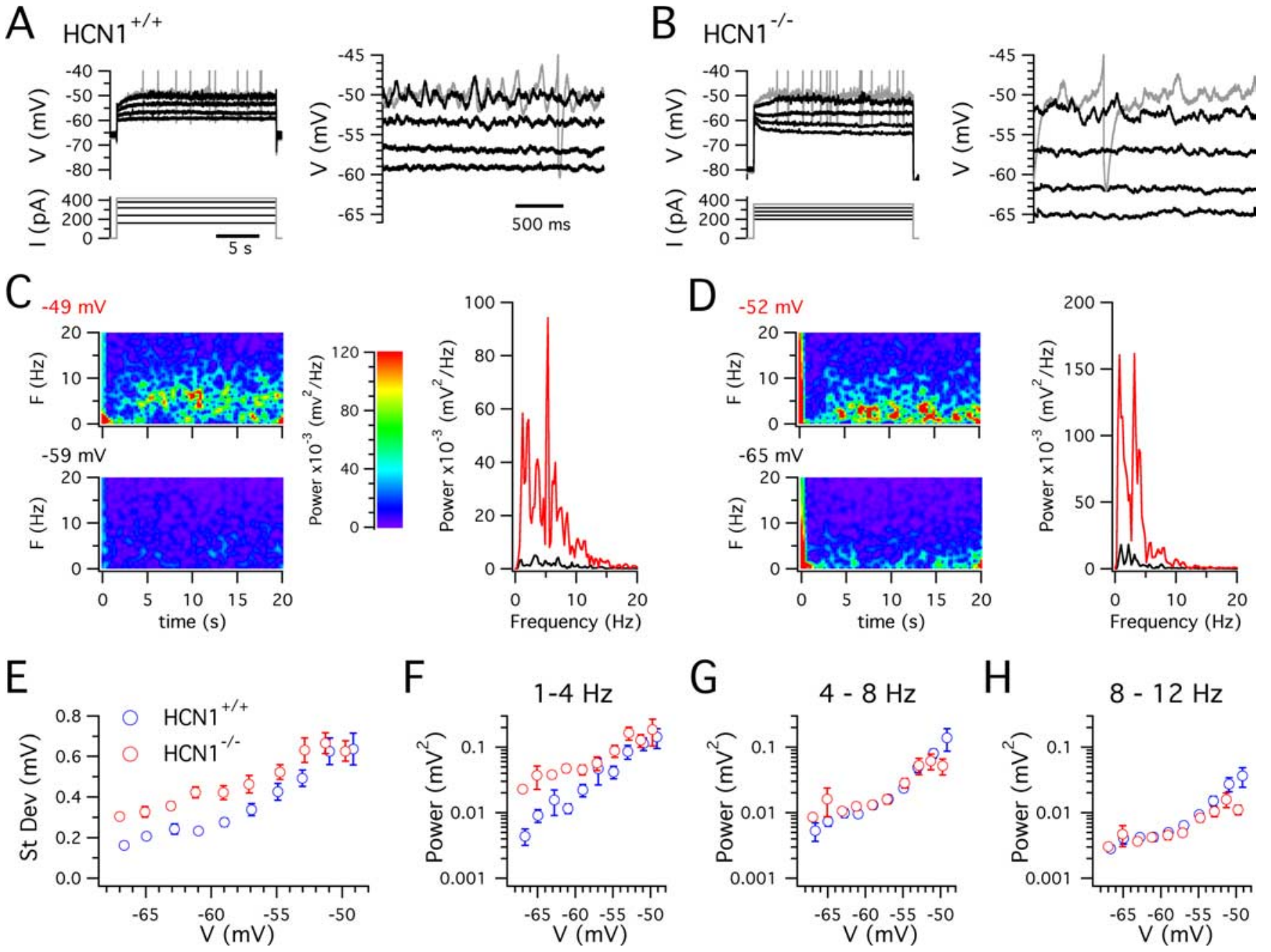

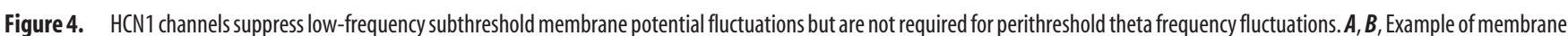
potential responses of stellate cells from $\mathrm{HCN1}^{+/+}(\boldsymbol{A})$ and $\mathrm{HCN1}^{-/-}(\boldsymbol{B})$ mice to series of positive current steps. Responses that contain spikes are in gray. For clarity, only a subset of the responses are shown. Traces on the right show a section of the same data on an expanded time base. $\boldsymbol{C}, \boldsymbol{D}$, Spectrograms (left) of membrane potential activity from depolarized (top left) and relatively hyperpolarized (bottom left) traces and corresponding power spectra (right) for the data in $\boldsymbol{A}$ and $\boldsymbol{B}$. The zero time point in each spectrogram corresponds to the onset of the positive current step. The power spectra are for the membrane potential fluctuations from 4 to 20 s after the onset of the current step. In each spectrogram, the relative power is plotted as a function of time (abscissa) and frequency (ordinate). $E, S D$ of the membrane potential plotted as a function of mean membrane potential. ANOVA revealed a significant effect of genotype ( $p=5.8 \mathrm{e}-13)$, membrane potential $(p=2.2 \mathrm{e}-16)$, and interaction between genotype and membrane potential $(p=0.028)$. Subsequent $t$ tests indicated significant $(p<0.05)$ differences between $H C N 1^{+/+}$and $H C N 1^{-/-}$mice at potentials negative to $-56 \mathrm{mV} . \boldsymbol{F}-\boldsymbol{H}$, Mean power in the range of $1-4 \mathrm{~Hz}(\boldsymbol{F}), 4-8 \mathrm{~Hz}(\boldsymbol{G})$, and $8-12 \mathrm{~Hz}(\boldsymbol{H})$ plotted as a function of membrane potential. ANOVA revealed a significant effect of genotype and membrane potential in the $1-4 \mathrm{~Hz}$ band (genotype, $p=1.8 \mathrm{e}-05$; membrane potential, $p=3.6 \mathrm{e}-16$; interaction, 0.96 ) but only of membrane potential in the $4-8 \mathrm{~Hz}$ band (genotype, $p=0.92 ;$ membrane potential, $p=2.2 \mathrm{e}-16)$ and $8-12 \mathrm{~Hz}$ band (genotype, $p=0.0765$; membrane potential, $p=2.2 \mathrm{e}-16)$. Subsequent $t$ tests revealed a significant difference $(p<0.05)$ in the SD of the membrane potential between $\mathrm{HCN1}^{+/+}$and $\mathrm{HCN1}^{-/-}$mice in the $1-4 \mathrm{~Hz}$ band at potentials negative to $-54 \mathrm{mV}$ but no difference at any potential in the $4-8$ or $8-12 \mathrm{~Hz}$ bands.

component of the action potential. Rather, these data are consistent with an inward current mediated by HCN1 channels acting during the AHP to promote rapid recovery of the AHP and thereby increasing the probability of a subsequent spike.

\section{Discussion}

To better understand the neural circuitry that gives rise to inputs to the hippocampus, we investigated how HCN1 channels influence the integrative properties of stellate neurons from layer II of the medial entorhinal cortex. We found that HCN1 channels in these neurons are required for a large, fast component of $I_{\mathrm{h}}$ and influence resting and active membrane properties. When stellate cells are in resting states, $\mathrm{HCN} 1$ channels dominate the membrane conductance and suppress low frequency fluctuations in membrane potential, whereas during active states, HCN1 channels control the pattern of spike output by promoting repolariza- tion of the AHP. We suggest how HCN1 channels in stellate cells could play roles in forms of memory that rely on precise temporal patterns of input to the hippocampal dentate gyrus.

HCN1 channels dominate the resting membrane properties of MEC layer II stellate cells

Together, our data indicate that HCN1 channels dominate the resting membrane properties of stellate cells from layer II of the MEC. We found that HCN1 channels are required for rapid and full activation of the large $I_{\mathrm{h}}$ present in stellate neurons. Comparison of the resting membrane properties of stellate cells from $\mathrm{HCN1}^{+/+}$and $\mathrm{HCN1}^{-/-}$mice supports a model whereby steadystate activation of $\mathrm{HCN} 1$ channels contributes to the resting membrane potential, input resistance, and time constant, whereas voltage-dependent gating of $\mathrm{HCN} 1$ channels actively opposes deviations of the membrane potential away from rest. The 


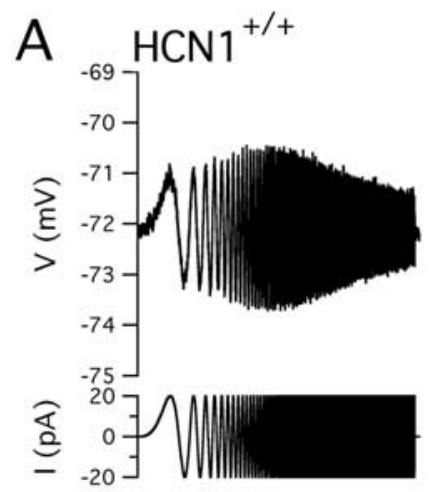

B
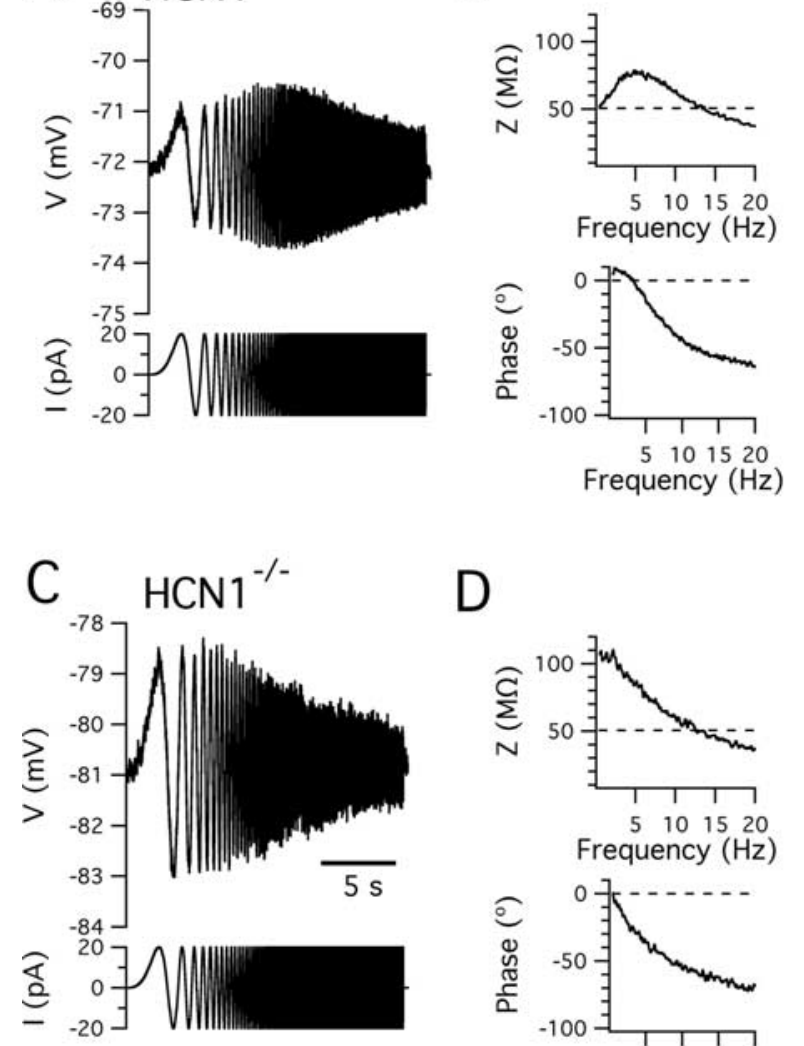

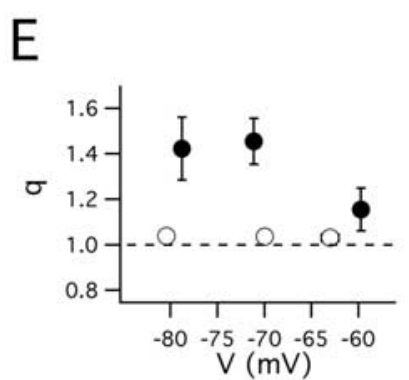

$\mathrm{F}$
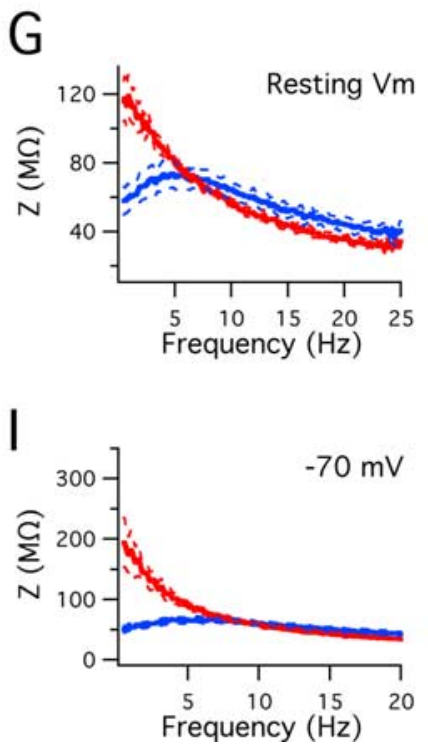
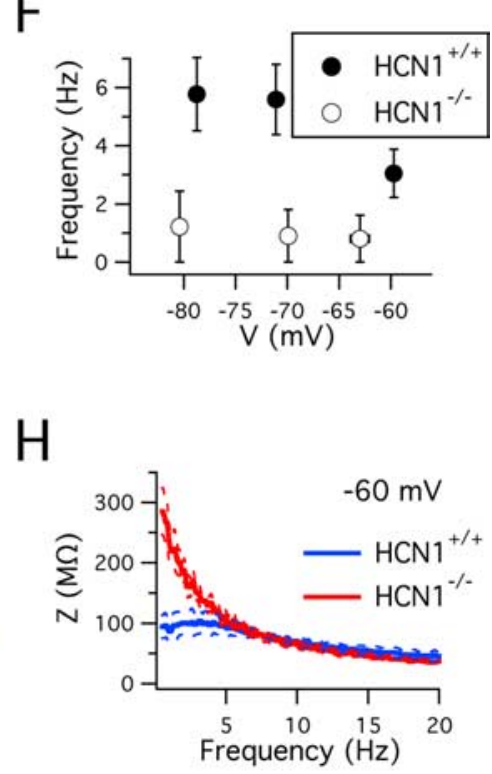

$\mathrm{J}$

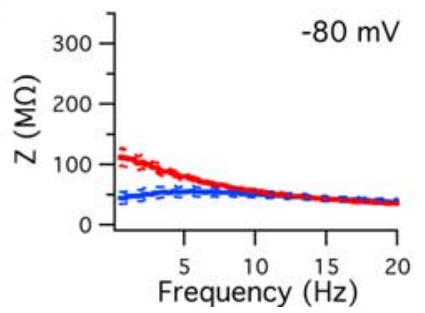

Figure 5. Deletion of HCN1 channels increases membrane impedance in response to low-frequency inputs $(<4 \mathrm{~Hz})$ but not to theta frequency inputs $(4-12 \mathrm{~Hz}) . \boldsymbol{A}, \boldsymbol{C}$, Examples of membrane potential responses (top) to injection of ZAP current waveforms (bottom) for stellate neurons from $\mathrm{HCN1}^{+/+}(\boldsymbol{A})$ and $\mathrm{HCN1}^{-/-}(\boldsymbol{C})$ mice. The ZAP waveform is a sinusoid with continuously increasing frequency and a constant peak to peak amplitude. $\boldsymbol{B}, \boldsymbol{D}$, Plot of membrane impedance amplitude ( $Z$ ) (top) and phase (bottom) as a function of frequency obtained from the data in $\boldsymbol{A}$ and C (for additional details, see Materials and Methods). $\boldsymbol{E}$, Mean relative amplitude of the resonance peak ( $q$ ) plotted as a function of membrane potential (each point is the mean of values from $3-5$ different cells). To calculate $q$, the maximal value of $Z$ was divided by the value of $Z$ at a frequency of $0.5 \mathrm{~Hz}$. ANOVA reveled a significant effect of genotype $(p=0.009)$ but not membrane potential $(p=0.81) . \boldsymbol{F}$, Plot of the mean frequency at which the resonance peak is found as a function of membrane potential. ANOVA revealed significant effects of genotype $(p=0.001)$ and membrane potential ( $p=0.037$ ) and an interaction between genotype and membrane potential ( $p=0.035)$. $\mathbf{G}-\mathbf{J}$, Mean of the membrane impedance plotted as a function of frequency at resting membrane potential $(\boldsymbol{G}),-60 \mathrm{mV}(\boldsymbol{H}),-70 \mathrm{mV}(\boldsymbol{I})$, and $-80 \mathrm{mV}(\boldsymbol{J})(n=3-5$ cells for each trace). Dashed lines indicate the SEM. Using Student's $t$ test to compare the impedance amplitude at each individual frequency, we found significant $(p<0.05)$ differences between $H C N 1^{+/+}$and $H C N 1^{-/-}$mice at frequencies $<3.5 \mathrm{~Hz}(\boldsymbol{G}),<2.9 \mathrm{~Hz}(\boldsymbol{H}),<6.3 \mathrm{~Hz}(\boldsymbol{I})$, and $<5.1 \mathrm{~Hz}(\boldsymbol{J})$.

relatively steep voltage dependence of the wild-type $I_{\mathrm{h}}$ may be particularly important for this stabilizing action. Similar effects on resting integrative properties are caused by deletion of HCN1 channels from pyramidal cells (Nolan et al., 2004) or by pharmacological block of $I_{\mathrm{h}}$ in either type of neuron (Klink and Alonso, 1993; Jones, 1994; Gasparini and DiFrancesco, 1997; Magee, 1998; Stuart and Spruston, 1998; van Der Linden et al., 1999; Dickson et al., 2000; Williams and Stuart, 2000; Day et al., 2005). Therefore, these may be common consequences of HCN1 expression in neurons with hyperpolarized resting potentials. In contrast, in cerebellar Purkinje cells, which are spontaneously active and have relatively depolarized membrane potentials, HCN1 channels do not appear to influence spontaneous activity, rather they are activated by hyperpolarizing inputs (Williams et al., 2002) and ensure that the relationship between input strength and spike output is independent of the previous history of activity (Nolan et al., 2003).

\section{During activation of stellate cells, HCN1 channels control patterns of spike output by promoting repolarization of the action potential AHP}

In contrast to their effects on resting membrane properties, the influence of HCN1 channels on the pattern of neuronal spike output has received relatively little attention. Our data support a novel function for HCN1 channels to determine the pattern of spike firing during active states: the inward current mediated by activation of HCN1 channels during the spike AHP promotes repolarization of the membrane potential toward the spike threshold, which in turn increases the probability that a second spike will be initiated soon after the first spike. Although our voltage-clamp experiments predict that the fraction of open HCN1 channels would be relatively small at membrane potentials obtained during the spike AHP (Fig. 2), the membrane slope conductance is also likely to be very small at these potentials (Koch, 1999; Waters and Helmchen, 2006). As a result, relatively small HCN-mediated currents may shift the balance between inward and outward currents during the AHP and therefore lead to substantial changes in the membrane potential trajectory.

When stellate neurons are activated by continuous depolarization, they fire action potentials organized into clustered patterns (Alonso and Klink, 1993; White et al., 1998). Although $\mathrm{HCN} 1$ channels are not required for clustered patterns of spiking to emerge and the mechanisms that initiate and curtail spike clusters remain unclear, in the absence of HCN1 channels, the propensity to fire clusters and the frequency of spikes within 
clusters is reduced (Fig. 6). This change in the pattern of firing is accounted for by the increased duration of the AHP (Fig. 7). HCN1 channels may also influence the pattern of spontaneous firing by neurons in the globus pallidus, although in this case, the AHP after each spike does not activate $I_{\mathrm{h}}$, but rather activation of inhibitory synaptic inputs is required to provide the hyperpolarization necessary for activation of $I_{\mathrm{h}}$ (Chan et al., 2004). Additional investigation is required to establish the roles of other ion channels in the genesis of clustered patterns of spike firing, to determine whether stellate cells fire spikes in clustered patterns when they are activated in vivo, and if so, what impact this has on their downstream targets in the dentate gyrus.

\section{Does deletion of HCN1 channels alter expression of other membrane ion channels?}

Although the differences that we found between the electrophysiological properties of stellate cells from $\mathrm{HCN}^{+/+}$and $\mathrm{HCN1}^{-1-}$ mice are consistent with direct effects of removing HCN1 channels from the cell membrane, it is nevertheless important to consider whether deletion of HCN1 channels could have indirectly caused changes in expression of other ion channels that would support alternative explanations for our data. Several lines of evidence indicate this is not the case. First, the resting membrane properties of $\mathrm{HCN1}^{+/+}$and $\mathrm{HCN1}^{-/-}$mice were indistinguishable after complete block of $I_{\mathrm{h}}$ with ZD7288 (Fig. 3), whereas if expression of ion channels from outside the $\mathrm{HCN}$ family were altered, then differences should be maintained after block of $I_{\mathrm{h}}$. Second, in $\mathrm{HCN1}^{-/-}$mice, only a small residual $I_{\mathrm{h}}$ is found in stellate cells (Fig. 2), suggesting that no major upregulation of other HCN subunits occurs in these cells in response to the deletion of HCN1. Third, the absence of any differences in the action potential voltage waveform or threshold after deletion of $\mathrm{HCN} 1$ channels (supplemental Fig. 3, available at www. jneurosci.org as supplemental material) indicates that the properties of voltagegated sodium and potassium channels are not substantially different in the two groups of mice. Fourth, direct measurement of the persistent sodium current, which strongly influences the perithreshold properties of stellate cells, also failed to reveal differences between $\mathrm{HCN1}^{+/+}$and $\mathrm{HCN1}^{-/-}$mice (supplemental Fig. 2, available at www.jneurosci.org as supplemental material). Finally, any secondary

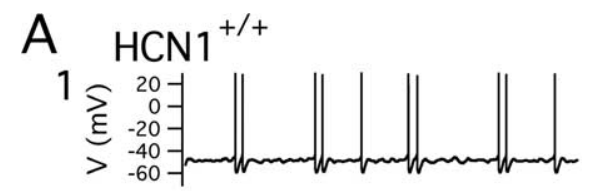

B $\mathrm{HCN}^{-1-}$
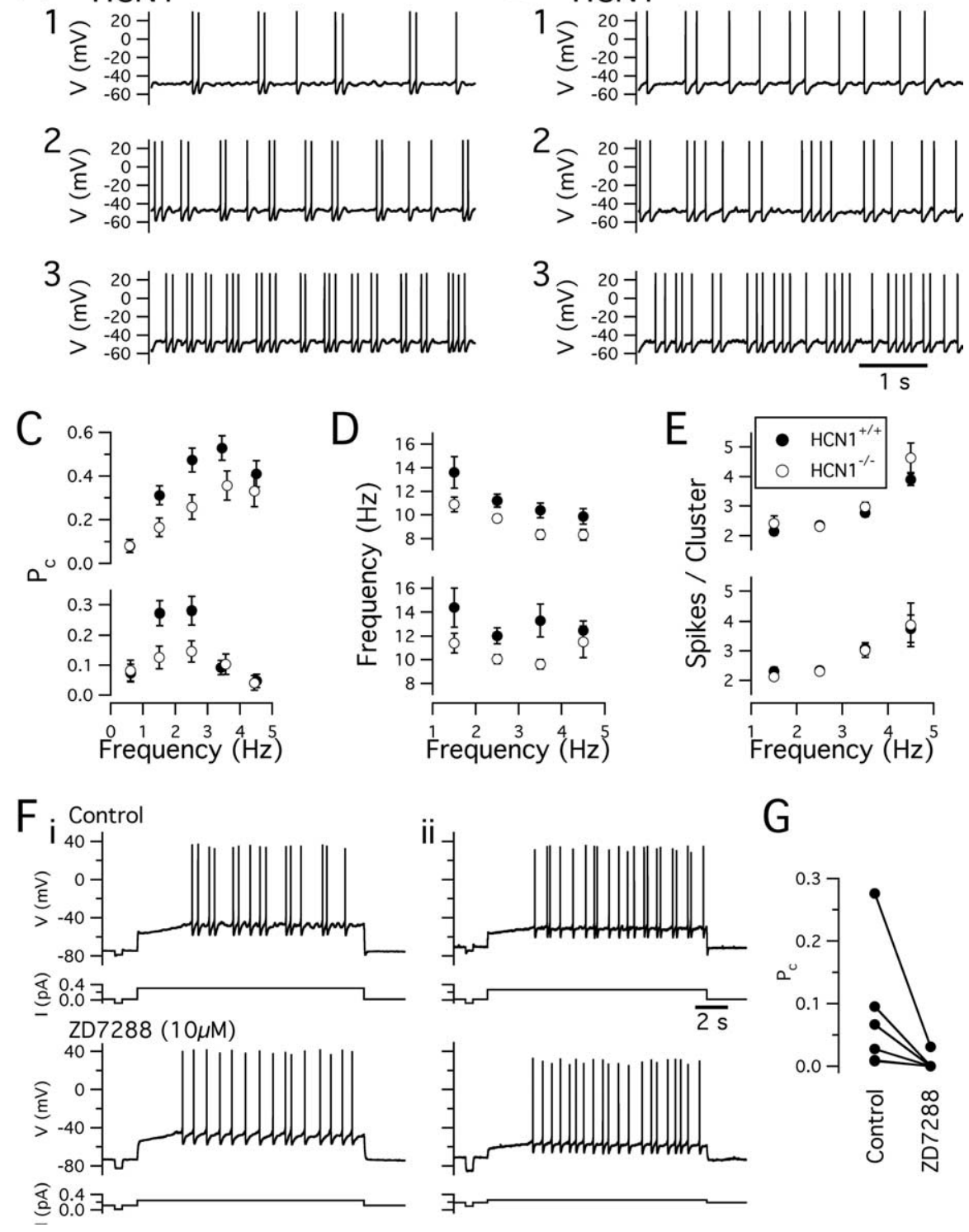

G

Figure 6. Patterns of spike output are altered by deletion of $\mathrm{HCN} 1$ channels. $A, B$, Examples of the patterns of action potentials fired by MEC layer II stellate cells during injection of positive current steps. Traces show the membrane potential of neurons from $H C N 1^{+/+}(A)$ and $\mathrm{HCN1}^{-/-}(B)$ mice in response to different levels of current input. Each trace shows the membrane potential from 5 to $10 \mathrm{~s}$ after the onset of a $20 \mathrm{~s}$ duration current step. $C$, Mean values of $P_{C}$ plotted as a function of average spike frequency. In $\boldsymbol{C}-\boldsymbol{E}$, the top plots use a relaxed cluster definition, whereas the bottom plots use a more stringent definition (see Materials and Methods). ANOVA reveals a significant effect of genotype ( $p=0.0024$ and $p=0.0006$ for stringent and relaxed cluster definitions, respectively), an effect of spike frequency ( $p=0.063$ and $p=2.8 \mathrm{e}-11$ ), but no significant interaction between the two parameters ( $p=0.23$ and $p=0.47$ ). Because the distribution of $P_{c}$ in some frequency bands deviated from normality (ShapiroWilk test; $p<0.05$ ), we performed several additional nonparametric tests on the data with the stringent cluster definition, which indicate that $P_{C}$ depends on frequency in the $\mathrm{HCN1}^{+/+}$but not the $\mathrm{HCN1}^{-/-}$group (Kruskal-Wallis rank sum test; $p=1.5 \mathrm{e}-4$ and $p=0.12$, respectively) and that $P_{C}$ differs between neurons from $\mathrm{HCN1}^{+/+}$and $\mathrm{HCN1}^{-/-}$mice at frequencies of $1-2$ and $2-3 \mathrm{~Hz}$ (Wilcoxon rank sum test; $p=0.008$ and $p=0.04$, respectively). $\boldsymbol{D}$, The average intracluster spike frequency plotted as a function of average spike frequency during the analysis period. ANOVA indicated a significant effect of genotype ( $p<0.01$ for both cluster definitions) and of overall spike frequency ( $p=0.026$ and $p=0.0002$ for stringent and relaxed cluster definitions, respectively). $\boldsymbol{E}$, The number of spikes per cluster plotted as a function of average spike frequency. ANOVA reveals a significant effect of overall spike frequency ( $p<1.5 \mathrm{e}-9$ for both cluster definitions) and a possible effect of genotype ( $p=0.026$ and $p=0.054)$. $\boldsymbol{F}$, Examples of membrane potential responses (top traces in each plot) to current steps (bottom traces) recorded from two different stellate cells (i-ii) in control condition (top plots) and during perfusion of $10 \mu \mathrm{m}$ ZD7288 (bottom plots). $\mathbf{G}$, The probability that spikes occur as part of a cluster $\left(P_{c}\right)$ for six stellate cells recorded in control conditions and subsequently in the presence of $10 \mu \mathrm{m}$ ZD7288. The mean value of $P_{C}$ decreased from $0.08 \pm 0.04$ in control conditions to $0.005 \pm 0.005$ during perfusion of ZD7288 ( $p=0.031$; Wilcoxon signed rank test). The average frequency of spikes during steps used for comparison of firing patterns was $1.13 \pm 0.16 \mathrm{~Hz}$ in control conditions and $1.19 \pm 0.1 \mathrm{~Hz}$ during perfusion of $\mathrm{ZD7288}$ ( $p=0.69$; Wilcoxon signed rank test). 


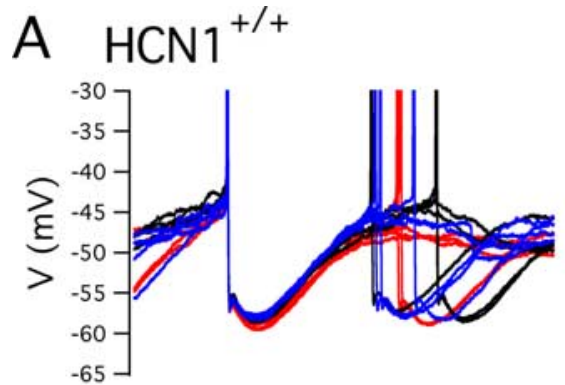

C $\mathrm{HCN1}^{-/-}$

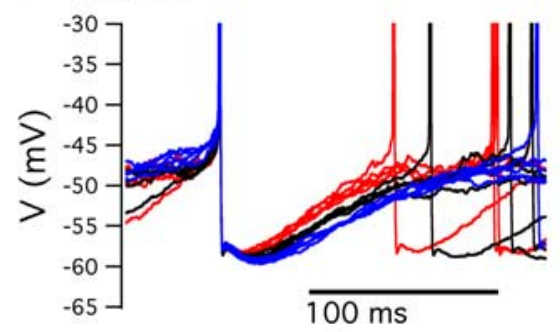

$\mathrm{E}$

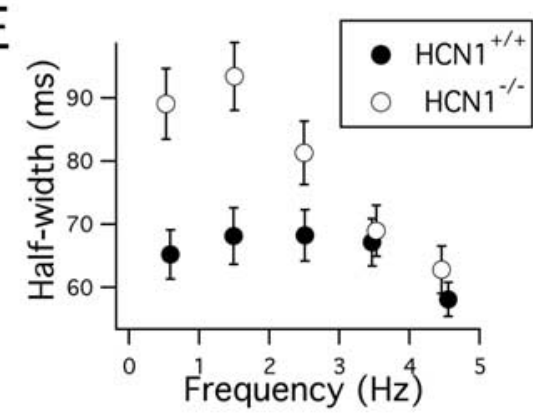

G

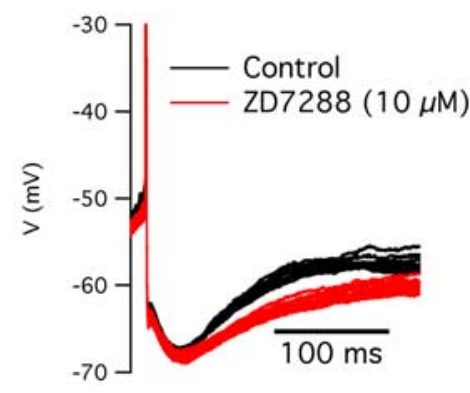

B

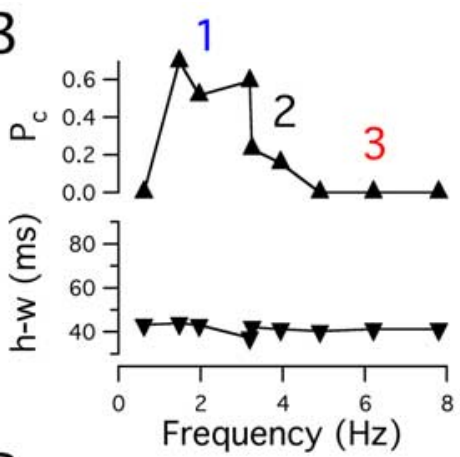

D

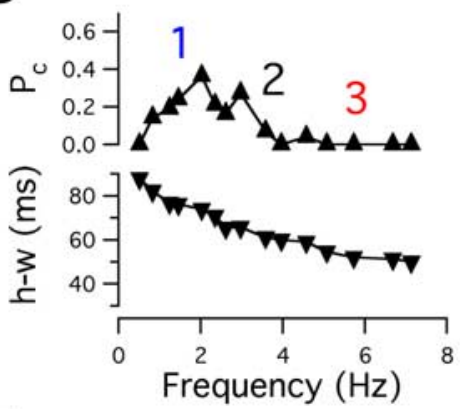

$\mathrm{F}$

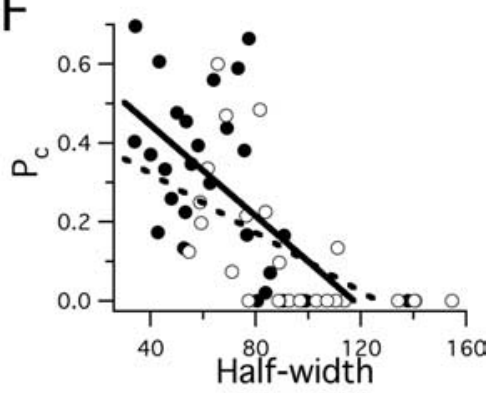

$\mathrm{H}$

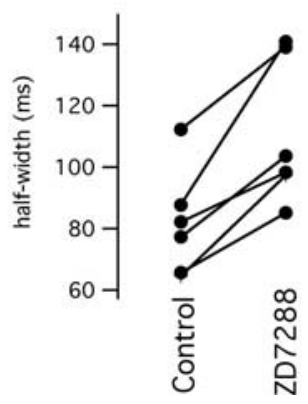

Figure 7. HCN1 channels control the pattern of spike firing by promoting repolarization of the action potential AHP. A, Afterhyperpolarizations after five consecutive action potentials of each trace in Figure $6 A$ aligned to the rising phase of the action potential (blue, $560 \mathrm{pA} \mathrm{step;} \mathrm{black,} 520 \mathrm{pA} \mathrm{step;} \mathrm{red,} 460 \mathrm{pA} \mathrm{step).} \boldsymbol{B}$, The probability that a spike fired by the $\mathrm{HCN1}^{+/+}$neuron in $\boldsymbol{A}$ is part of a cluster using the stringent definition $\left(P_{C}\right)$ and the mean half-width of the afterhyperpolarization $(\mathrm{h}-\mathrm{w})$ are plotted as a function of the average spike frequency during each current step. The numbers above the points correspond to the data shown in $A$ (current steps: 1 , $460 \mathrm{pA} ; 2,520 \mathrm{pA} ; 3,560 \mathrm{pA}) . \boldsymbol{C}, \boldsymbol{D}$, Data from the $H C N 1^{-1-}$ neuron in Figure $6 B$ are plotted as for $A$ and $B$. The numbers above the points in D correspond to the data shown in C (current steps: $1,440 \mathrm{pA} ; 2,500 \mathrm{pA} ; 3,580 \mathrm{pA}$ ). $\boldsymbol{E}$, Half-width of the action potential AHP plotted as a function of average spike frequency. ANOVA indicates a significant effect of average spike frequency $(p=2.3 \mathrm{e}-05)$ and genotype ( $p=2.4 \mathrm{e}-07$ ) and an interaction between genotype and average spike frequency $(p=0.006)$. Differences between $\mathrm{HCN1}^{+/+}$and $\mathrm{HCN1}^{-/-}$mice were significant $(t$ test; $p<0.05)$ at frequencies $<3 \mathrm{~Hz}$. In the $\mathrm{HCN}^{+/+}$group, there were no effects of average spike frequency $(p>0.05)$, whereas in the $\mathrm{HCN1}^{-1-}$ group, the AHP half-width at frequencies $>3 \mathrm{~Hz}$ was smaller than the AHP at frequencies $<2 \mathrm{~Hz}$ (Tukey's honestly significant difference test; $p<0.05$ ). $\boldsymbol{F}$, Probability that spikes are part of cluster patterns using the stringent definition $\left(P_{C}\right)$ plotted as a function of the mean AHP half-width for spikes firing at average frequencies between 1 and $2 \mathrm{~Hz}$. Regression lines are for $\mathrm{HCN}^{+/+}$(solid line; $y=0.68-0.0058 x$; adjusted $r=0.36 ; p=0.0003$ ) and $\mathrm{HCN1}^{-/-}$ (dashed line; $y=0.47-0.0037 x$; adjusted $r=0.31 ; p=0.002$ ). G, Examples of action potentials from a stellate cell in control conditions (black traces) and during perfusion of $10 \mu \mathrm{m} Z \mathrm{ZD} 7288$ (red traces). $\boldsymbol{H}$, Plot of the action potential half-duration from the six experiments in control conditions and during subsequent perfusion of $10 \mu \mathrm{m} \mathrm{ZD7288.} \mathrm{The} \mathrm{mean} \mathrm{half-width} \mathrm{was} \mathrm{increased} \mathrm{from}$ $81.6 \pm 7.2 \mathrm{~ms}$ in control to $110.7 \pm 9.6 \mathrm{~ms}$ during perfusion of ZD7288 ( $p=0.031$; Wilcoxon signed rank test).

changes induced by loss of ion channel expression would be expected to compensate for the absence of that channel and therefore occlude demonstration of the normal function of that channel (Brickley et al., 2001). Thus, although it is difficult to completely rule out possible changes in expression of other ion channels after deletion of HCN1, there is no evidence to support this possibility. Moreover, if adaptive changes have occurred, they will likely have led us to underestimate the influence of $\mathrm{HCN} 1$ channels on entorhinal stellate cell function.

Behavioral and physiological implications of HCN1 channel expression for the functions of stellate cells

Different subregions of the medial temporal lobe that together support episodic forms of memory are thought to have distinct computational roles, such as pattern separation, pattern association, and pattern completion (Kesner et al., 2004). The dentate gyrus, which is the major target of stellate cells in layer II of the MEC, is believed to be important for spatial pattern separation, the encoding of similar spatial information into distinct representations. We suggest that $\mathrm{HCN} 1$ channels in stellate cells may facilitate pattern separation in the dentate gyrus through two mechanisms. First, when the membrane potential of a stellate cell is close to rest, $\mathrm{HCN} 1$ channels may modify the time window over which integration of synaptic inputs initiate single action potentials (Magee, 1999) or subthreshold forms of synaptic plasticity (Alonso et al., 1990). Second, when stellate cells are in active states such that they are sufficiently depolarized to fire repeated action potentials, $\mathrm{HCN} 1$ channels may contribute to encoding of information by modifying the pattern of action potential output.

Does the absence of $\mathrm{HCN} 1$ channels from stellate cells in the MEC contribute to enhanced memory performance in mice with forebrain restricted deletion of the $\mathrm{HCN} 1$ channel (Nolan et al., 2004)? Although increased responsiveness of stellate cells from $\mathrm{HCN1}^{-1-}$ mice to low frequency inputs could enhance the access of low frequency signals to the hippocampal circuit, it is also possible that in the forms of spatial learning in which $\mathrm{HCN}^{-1-}$ mice have been tested thus far, the requirements for precise integration by stellate cells in the MEC may be minimal or may be masked by enhanced synaptic plasticity caused by deletion of $\mathrm{HCN} 1$ channels from pyramidal cells (Nolan et al., 2004). More restricted deletions of the HCN1 channel and behavioral paradigms that involve different subregions of the medial temporal lobe circuit will be required to distinguish among these and other possibilities. It will 
also be important to determine whether stellate cells demonstrate activity-dependent plasticity of HCN channels similar to that found in pyramidal cells (Shah et al., 2004; Fan et al., 2005), because this may modify the integrative functions described here and could contribute to forms of epilepsy in which both the entorhinal cortex and HCN channels have been implicated (Poolos, 2005).

\section{References}

Alonso A, Klink R (1993) Differential electroresponsiveness of stellate and pyramidal-like cells of medial entorhinal cortex layer II. J Neurophysiol 70:128-143.

Alonso A, Llinas RR (1989) Subthreshold Na+-dependent theta-like rhythmicity in stellate cells of entorhinal cortex layer II. Nature 342:175-177.

Alonso A, de Curtis M, Llinas R (1990) Postsynaptic Hebbian and nonHebbian long-term potentiation of synaptic efficacy in the entorhinal cortex in slices and in the isolated adult guinea pig brain. Proc Natl Acad Sci USA 87:9280-9284.

Amaral DG, Witter MP (1989) The three-dimensional organization of the hippocampal formation: a review of anatomical data. Neuroscience 31:571-591.

Bender RA, Kirschstein T, Kretz O, Brewster AL, Richichi C, Ruschenschmidt C, Shigemoto R, Beck H, Frotscher M, Baram TZ (2007) Localization of HCN1 channels to presynaptic compartments: novel plasticity that may contribute to hippocampal maturation. J Neurosci 27:4697-4706.

BoSmith RE, Briggs I, Sturgess NC (1993) Inhibitory actions of ZENECA ZD7288 on whole-cell hyperpolarization activated inward current (If) in guinea-pig dissociated sinoatrial node cells. Br J Pharmacol 110:343-349.

Brickley SG, Revilla V, Cull-Candy SG, Wisden W, Farrant M (2001) Adaptive regulation of neuronal excitability by a voltage- independent potassium conductance. Nature 409:88-92.

Buckmaster PS, Alonso A, Canfield DR, Amaral DG (2004) Dendritic morphology, local circuitry, and intrinsic electrophysiology of principal neurons in the entorhinal cortex of macaque monkeys. J Comp Neurol 470:317-329.

Chan CS, Shigemoto R, Mercer JN, Surmeier DJ (2004) HCN2 and HCN1 channels govern the regularity of autonomous pacemaking and synaptic resetting in globus pallidus neurons. J Neurosci 24:9921-9932.

Chen C (2004) ZD7288 inhibits postsynaptic glutamate receptor-mediated responses at hippocampal perforant path-granule cell synapses. Eur J Neurosci 19:643-649.

Chen S, Wang J, Siegelbaum SA (2001) Properties of hyperpolarizationactivated pacemaker current defined by coassembly of HCN1 and HCN2 subunits and basal modulation by cyclic nucleotide. J Gen Physiol 117:491-504.

Chevaleyre V, Castillo PE (2002) Assessing the role of Ih channels in synaptic transmission and mossy fiber LTP. Proc Natl Acad Sci USA 99:9538-9543.

Cossart R, Aronov D, Yuste R (2003) Attractor dynamics of network UP states in the neocortex. Nature 423:283-288.

Day M, Carr DB, Ulrich S, Ilijic E, Tkatch T, Surmeier DJ (2005) Dendritic excitability of mouse frontal cortex pyramidal neurons is shaped by the interaction among $\mathrm{HCN}$, Kir2, and Kleak channels. J Neurosci 25:8776-8787.

Dickson CT, Magistretti J, Shalinsky MH, Fransen E, Hasselmo ME, Alonso A (2000) Properties and role of $\mathrm{I}(\mathrm{h})$ in the pacing of subthreshold oscillations in entorhinal cortex layer II neurons. J Neurophysiol 83:2562-2579.

Do MT, Bean BP (2003) Subthreshold sodium currents and pacemaking of subthalamic neurons: modulation by slow inactivation. Neuron 39:109-120.

Dolorfo CL, Amaral DG (1998) Entorhinal cortex of the rat: organization of intrinsic connections. J Comp Neurol 398:49-82.

Dorval Jr AD, White JA (2005) Channel noise is essential for perithreshold oscillations in entorhinal stellate neurons. J Neurosci 25:10025-10028.

Erchova I, Kreck G, Heinemann U, Herz AV (2004) Dynamics of rat entorhinal cortex layer II and III cells: characteristics of membrane potential resonance at rest predict oscillation properties near threshold. J Physiol (Lond) 560:89-110.

Fan Y, Fricker D, Brager DH, Chen X, Lu HC, Chitwood RA, Johnston D (2005) Activity-dependent decrease of excitability in rat hippocampal neurons through increases in I(h). Nat Neurosci 8:1542-1551.
Felix R, Sandoval A, Sanchez D, Gomora JC, De la Vega-Beltran JL, Trevino CL, Darszon A (2003) ZD7288 inhibits low-threshold Ca(2+) channel activity and regulates sperm function. Biochem Biophys Res Commun 311:187-192.

Fransen E, Alonso AA, Dickson CT, Magistretti J, Hasselmo ME (2004) Ionic mechanisms in the generation of subthreshold oscillations and action potential clustering in entorhinal layer II stellate neurons. Hippocampus 14:368-384.

Fyhn M, Molden S, Witter MP, Moser EI, Moser MB (2004) Spatial representation in the entorhinal cortex. Science 305:1258-1264.

Gasparini S, DiFrancesco D (1997) Action of the hyperpolarizationactivated current (Ih) blocker ZD 7288 in hippocampal CA1 neurons. Pflügers Arch 435:99-106.

Giocomo LM, Zilli EA, Fransen E, Hasselmo ME (2007) Temporal frequency of subthreshold oscillations scales with entorhinal grid cell field spacing. Science 315:1719-1722.

Hafting T, Fyhn M, Molden S, Moser MB, Moser EI (2005) Microstructure of a spatial map in the entorhinal cortex. Nature 436:801-806.

Hutcheon B, Miura RM, Puil E (1996) Subthreshold membrane resonance in neocortical neurons. J Neurophysiol 76:683-697.

Jones RS (1994) Synaptic and intrinsic properties of neurons of origin of the perforant path in layer II of the rat entorhinal cortex in vitro. Hippocampus 4:335-353.

Kesner RP, Lee I, Gilbert P (2004) A behavioral assessment of hippocampal function based on a subregional analysis. Rev Neurosci 15:333-351.

Klink R, Alonso A (1993) Ionic mechanisms for the subthreshold oscillations and differential electroresponsiveness of medial entorhinal cortex layer II neurons. J Neurophysiol 70:144-157.

Klink R, Alonso A (1997) Morphological characteristics of layer II projection neurons in the rat medial entorhinal cortex. Hippocampus 7:571-583.

Koch C (1999) Biophysics of computation: information processing in single neurons. New York: Oxford UP.

Leutgeb S, Leutgeb JK, Moser MB, Moser EI (2005) Place cells, spatial maps and the population code for memory. Curr Opin Neurobiol 15:738-746.

Lorincz A, Notomi T, Tamas G, Shigemoto R, Nusser Z (2002) Polarized and compartment-dependent distribution of $\mathrm{HCN} 1$ in pyramidal cell dendrites. Nat Neurosci 5:1185-1193.

Maccaferri G, McBain CJ (1996) The hyperpolarization-activated current (Ih) and its contribution to pacemaker activity in rat CA1 hippocampal stratum oriens-alveus interneurones. J Physiol (Lond) 497:119-130.

Magee JC (1998) Dendritic hyperpolarization-activated currents modify the integrative properties of hippocampal CA1 pyramidal neurons. J Neurosci 18:7613-7624.

Magee JC (1999) Dendritic lh normalizes temporal summation in hippocampal CA1 neurons. Nat Neurosci 2:508-514.

Magee JC (2000) Dendritic integration of excitatory synaptic input. Nat Rev Neurosci 1:181-190.

Magistretti J, Ragsdale DS, Alonso A (1999) High conductance sustained single-channel activity responsible for the low-threshold persistent $\mathrm{Na}^{+}$ current in entorhinal cortex neurons. J Neurosci 19:7334-7341.

Nolan MF, Malleret G, Lee KH, Gibbs E, Dudman JT, Santoro B, Yin D, Thompson RF, Siegelbaum SA, Kandel ER, Morozov A (2003) The hyperpolarization-activated $\mathrm{HCN} 1$ channel is important for motor learning and neuronal integration by cerebellar Purkinje cells. Cell 115:551-564.

Nolan MF, Malleret G, Dudman JT, Buhl DL, Santoro B, Gibbs E, Vronskaya S, Buzsaki G, Siegelbaum SA, Kandel ER, Morozov A (2004) A behavioral role for dendritic integration: HCN1 channels constrain spatial memory and plasticity at inputs to distal dendrites of CA1 pyramidal neurons. Cell 119:719-732.

Notomi T, Shigemoto R (2004) Immunohistochemical localization of Ih channel subunits, HCN1-4, in the rat brain. J Comp Neurol 471:241-276.

Poolos NP (2005) The h-channel: a potential channelopathy in epilepsy? Epilepsy Behav 7:51-56.

Puil E, Gimbarzevsky B, Miura RM (1986) Quantification of membrane properties of trigeminal root ganglion neurons in guinea pigs. J Neurophysiol 55:995-1016.

Richter H, Heinemann U, Eder C (2000) Hyperpolarization-activated cation currents in stellate and pyramidal neurons of rat entorhinal cortex. Neurosci Lett 281:33-36.

Robinson RB, Siegelbaum SA (2003) Hyperpolarization-activated cation 
currents: from molecules to physiological function. Annu Rev Physiol 65:453-480.

Santoro B, Chen S, Luthi A, Pavlidis P, Shumyatsky GP, Tibbs GR, Siegelbaum SA (2000) Molecular and functional heterogeneity of hyperpolarization-activated pacemaker channels in the mouse CNS. J Neurosci 20:5264-5275.

Shah MM, Anderson AE, Leung V, Lin X, Johnston D (2004) Seizureinduced plasticity of $\mathrm{h}$ channels in entorhinal cortical layer III pyramidal neurons. Neuron 44:495-508.

Steriade M, Nunez A, Amzica F (1993) A novel slow ( $<1 \mathrm{~Hz}$ ) oscillation of neocortical neurons in vivo: depolarizing and hyperpolarizing components. J Neurosci 13:3252-3265.

Stuart G, Spruston N (1998) Determinants of voltage attenuation in neocortical pyramidal neuron dendrites. J Neurosci 18:3501-3510.

Ulens C, Tytgat J (2001) Functional heteromerization of HCN1 and HCN2 pacemaker channels. J Biol Chem 276:6069-6072.

Ulrich D (2002) Dendritic resonance in rat neocortical pyramidal cells. J Neurophysiol 87:2753-2759.

van Der Linden S, Panzica F, de Curtis M (1999) Carbachol induces fast oscillations in the medial but not in the lateral entorhinal cortex of the isolated guinea pig brain. J Neurophysiol 82:2441-2450.

van Groen T, Miettinen P, Kadish I (2003) The entorhinal cortex of the mouse: organization of the projection to the hippocampal formation. Hippocampus 13:133-149.
Wang M, Ramos BP, Paspalas CD, Shu Y, Simen A, Duque A, Vijayraghavan S, Brennan A, Dudley A, Nou E, Mazer JA, McCormick DA, Arnsten AF (2007) Alpha2A-adrenoceptors strengthen working memory networks by inhibiting cAMP-HCN channel signaling in prefrontal cortex. Cell 129:397-410

Waters J, Helmchen F (2006) Background synaptic activity is sparse in neocortex. J Neurosci 26:8267-8277.

White JA, Budde T, Kay AR (1995) A bifurcation analysis of neuronal subthreshold oscillations. Biophys J 69:1203-1217.

White JA, Klink R, Alonso A, Kay AR (1998) Noise from voltage-gated ion channels may influence neuronal dynamics in the entorhinal cortex. J Neurophysiol 80:262-269.

Williams SR, Stuart GJ (2000) Site independence of EPSP time course is mediated by dendritic $\mathrm{I}(\mathrm{h})$ in neocortical pyramidal neurons. J Neurophysiol 83:3177-3182.

Williams SR, Christensen SR, Stuart GJ, Hausser M (2002) Membrane potential bistability is controlled by the hyperpolarization-activated current $\mathrm{I}(\mathrm{H})$ in rat cerebellar Purkinje neurons in vitro. J Physiol (Lond) 539:469-483

Witter MP, Moser EI (2006) Spatial representation and the architecture of the entorhinal cortex. Trends Neurosci 29:671-678.

Witter MP, Wouterlood FG, Naber PA, Van Haeften T (2000) Anatomical organization of the parahippocampal-hippocampal network. Ann NY Acad Sci 911:1-24. 